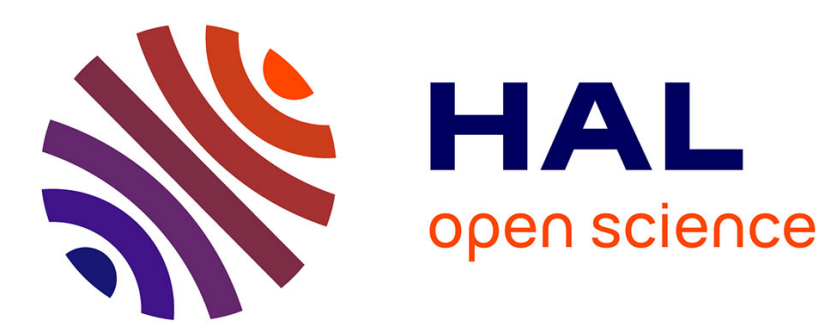

\title{
An application of the Bivariate Generalized Pareto Distribution for the probabilities of low flow extremes estimation
}

\author{
W. Jakubowski
}

\section{- To cite this version:}

W. Jakubowski. An application of the Bivariate Generalized Pareto Distribution for the probabilities of low flow extremes estimation. Hydrology and Earth System Sciences Discussions, 2006, 3 (3), pp.859-893. hal-00298702

\section{HAL Id: hal-00298702 \\ https://hal.science/hal-00298702}

Submitted on 6 Jun 2006

HAL is a multi-disciplinary open access archive for the deposit and dissemination of scientific research documents, whether they are published or not. The documents may come from teaching and research institutions in France or abroad, or from public or private research centers.
L'archive ouverte pluridisciplinaire HAL, est destinée au dépôt et à la diffusion de documents scientifiques de niveau recherche, publiés ou non, émanant des établissements d'enseignement et de recherche français ou étrangers, des laboratoires publics ou privés. 
Hydrol. Earth Syst. Sci. Discuss., 3, 859-893, 2006 www.hydrol-earth-syst-sci-discuss.net/3/859/2006/

(C) Author(s) 2006. This work is licensed under a Creative Commons License.
Hydrology and Earth System Sciences Discussions

Papers published in Hydrology and Earth System Sciences Discussions are under open-access review for the journal Hydrology and Earth System Sciences

\section{An application of the Bivariate Generalized Pareto Distribution for the probabilities of low flow extremes estimation}

\section{W. Jakubowski}

Dept. of Mathematics, Agricultural University of Wroclaw, Poland

Received: 3 March 2006 - Accepted: 23 March 2006 - Published: 6 June 2006

Correspondence to: W. Jakubowski (wj@ozi.ar.wroc.pl)

\section{HESSD}

3, 859-893, 2006

Bivariate distribution of the low flow extremes estimation

W. Jakubowski

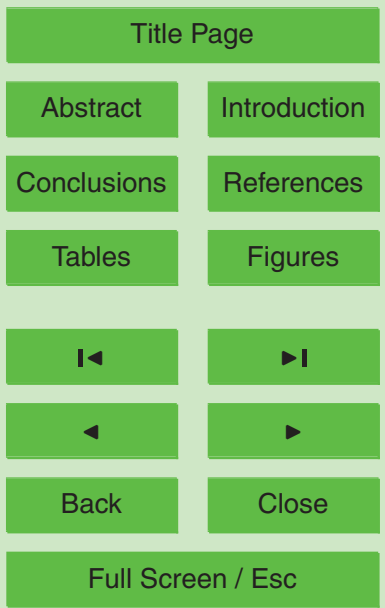

Printer-friendly Version

Interactive Discussion 


\section{Abstract}

The two-dimensional Bivariate Generalized Pareto Distribution (BGPD) of Tajvidi (1996) is applied in order to estimate the extreme values of the low flow deficit amounts and durations probabilities. Eight parameters BGPD depends on two one-dimensional

5 distributions - Univariate Generalized Pareto Distributions (UGPDs). Each of these three parameter UGPDs describes the probability of one of low flow indices. To fit BGPD into observed data a three steps method of estimation is proposed: (1) For a given shift parameter of each UGPD two others are estimated by the maximum likelihood method. (2) For given shifts and the UGPD parameters estimated in the first also estimated by the maximum likelihood method. (3) The best shift pair is chosen by maximization of the correlation coefficient of the estimated BGPD. The results are applied to statistical description of the low flow index extremes behaviour at four different catchments profiles. To extract the low flow time series data the standard constant 15 threshold level method is applied. Finally the estimated probabilities are compared to the Zelenhasić and Salvai (1987) model.

\section{Introduction}

Before starting the statistical elaboration of a low flow characteristic extreme, a method of the low flow indices extracting have to be chosen. It should be determined which flows are low and how the seasonality effects on the extracted low flows data time series. Then proper low flow indices should be defined. Full description of the low flow definitions can be found in monograph edited by Tallaksen and van Lanen (2004). Here only the indices extracted by the constant threshold level method are considered and probabilities of their extremes are estimated. To obtain such probabilities the two-
HESSD

3, 859-893, 2006

Bivariate distribution of the low flow extremes estimation

W. Jakubowski

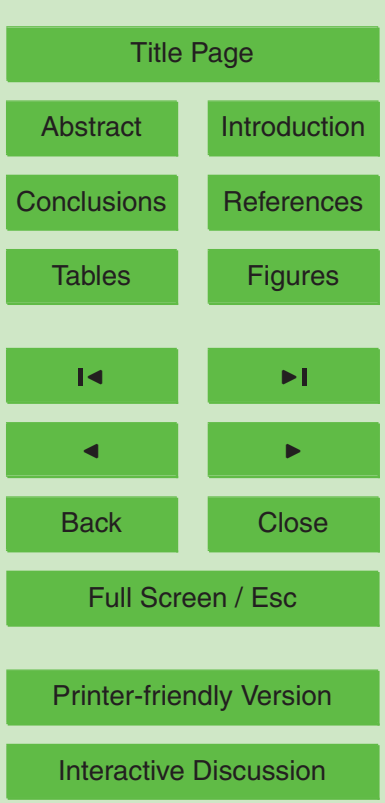




\section{Low flow definition}

By using the threshold level method two sequences of low flow indices can be determined from the time series of daily runoffs:

- deficit volumes [in $\mathrm{m}^{3}$ ]: $D_{n}=\int_{t_{n_{0}}}^{t_{n_{1}}}\left(Q_{L}-Q(t)\right) d t$;

5

- durations [in days]: $T_{n}=t_{n_{1}}-t_{n_{0}}+1$,

where $t_{n_{1}}$ is the n-th low flow of the last day, $t_{n_{0}}$ is the $n$-th low flow of the first day, $Q(t)$ stands for the runoff of t-th day, and $Q_{L}$ is the threshold level.

In practice, such low flows time series consist of a big number of minor observations often mutually dependent on one another. That is why additional criteria should

be applied. Following Zelenhasic and Salvai (1987), the following restrictions can be imposed; a single drought with duration shorter then the minimum drought duration or with a deficit lower then $\alpha D_{\max }$ are removed from the extracted low flow time series. Here $D_{\max }$ denotes the observed maximum deficit and the fractional coefficient $\alpha$ are often set to 0.005 . The next restriction is set in the form of the inter-drought criterion: two droughts separated by an interval lasting shorter then the critical duration are pooled to one another. An example of a typical low flow series observed on the Odra River (years 1982-1984) in the Polish Lowland ${ }^{1}$ is presented in Fig. 1.

\section{Univariate Generalized Pareto Distribution of low flow indices maximum}

Let $\left\{A_{i}\right\}_{i=1, \ldots, n}$ be a sequence of mutually independent, identically distributed random variables with distribution $F(x)=\operatorname{Pr}\left(A_{i} \leq x\right)$. Sequence $\left\{A_{i}\right\}_{i=1, \ldots, n}$ stands either for

\footnotetext{
${ }^{1}$ Daily runoff data are obtained from Institute of Meteorology and Water Management, Wroclaw Branch, Poland.
}

\section{HESSD}

3, 859-893, 2006

Bivariate distribution of the low flow

extremes estimation

W. Jakubowski

Title Page

Abstract

Introduction

Conclusions

References

Tables

Figures

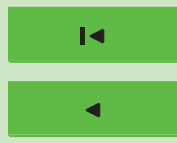

$\rightarrow 1$

Back

Close

Full Screen / Esc

Printer-friendly Version

Interactive Discussion 
deficit volume or its duration. In order to determine of maximum values $\max _{i=1, \ldots, n} A_{i}=M_{n}$ the Univariate Generalized Pareto Distribution (UGPD) can be applied.

HESSD

As in the work of Pickands (1975) UGPD is defined for $k<0$ as follows:

3, 859-893, 2006

$H(x, \kappa, \sigma)=1-\left(1-\kappa \frac{x}{\sigma}\right)^{\frac{1}{k}}, \quad \bar{H}=1-H$,

5 It can be applied to determining the probability of the extremes estimation if and only if

$\lim _{b \rightarrow x_{F}} \inf _{0<\sigma<\infty} \sup _{0 \leq x<\infty}\left|F_{b}(x)-H(x, \kappa, \sigma)\right|=0$,

where: $F_{b}(x)=\operatorname{Pr}(A<x+b \mid A>b)$ denotes the conditional distribution of the excess of the random variable $A=A_{i}, i=1, \ldots, n$, over the threshold $b$ on the condition that $x_{F}=\sup \{x: F(x)<1\}$. The above limit (2) is equal to 0 under the assumption that for any $a_{n}>0$ and $b_{n}$ there exists the limit

$\lim _{n \rightarrow \infty} \operatorname{Pr}\left(\frac{M_{n}-b_{n}}{a_{n}} \leq x\right)=\lim _{n \rightarrow \infty} F^{n}\left(a_{n} x+b_{n}\right)=G(x)$,

and $G(x)$ is a non-degenerate distribution function. Let us mention that $G(x)$ is called the Generalized Extreme Value Distribution.

For further investigation we denote by

$15 H_{b}(x, k, \alpha)=1-(1-\alpha \kappa(x+b))^{\frac{1}{\kappa}}, \quad x \geq 0, \alpha>0, k<0$,

the shifted three parameter UGPD with transformed scale parameter $\alpha$. It is easy to verify that the conditional distribution

$$
\begin{aligned}
\operatorname{Pr}(A \leq x+\beta \mid A>\beta) & =\frac{H_{b}(x+\beta, \kappa, \alpha)-H_{b}(\beta, \kappa, \alpha)}{1-H_{b}(\beta, \kappa, \alpha)} \\
& =1-\left(1-\frac{\alpha}{1-\alpha \kappa(b+\beta)} K x\right)^{\frac{1}{\kappa}}=H_{0}\left(x, \kappa, \alpha_{b+\beta}\right)
\end{aligned}
$$

Bivariate distribution of the low flow extremes estimation

W. Jakubowski

Title Page

Abstract Introduction

Conclusions References

Tables Figures

14 $>$ I

4

Back

Close

Full Screen / Esc

Printer-friendly Version

Interactive Discussion 
is also a UGPD with another scale parameter and shift parameter $b=0$. The expected values for the probability density function $h_{0}(x, \kappa, \alpha)$ of $H_{0}(x, \kappa, \alpha)$ can be obtained by

$$
E A=\int_{0}^{\infty} x h_{0}\left(x, k, \alpha_{b}\right) d x=\frac{1}{\alpha_{b}(k+1)}, \quad \text { for } k \in(-1 ; 0) \text {, }
$$$$
E A^{2}=\int_{0}^{\infty} x^{2} h_{0}\left(x, k, \alpha_{b}\right) d x=\frac{2}{\alpha_{b}^{2}(k+1)(2 \kappa+1)}, \quad \text { for } k \in(-0,5 ; 0) \text {, }
$$

$$
E(A \mid A>\beta)=\frac{1-\alpha_{b} \kappa \beta}{\alpha_{b}(\kappa+1)}=\frac{1}{\alpha_{b}(\kappa+1)}-\frac{\kappa \beta}{(\kappa+1)}, \quad \text { for } \kappa \in(-1 ; 0) \text {. }
$$

\section{Note that}

- the expected values are finite only for limited values of $k$;

- $E(A \mid a>\beta)$ is a linear function of $\beta$. It means that in stable conditions the expected value $E A$ obtained for different shifts $b$ should grow similarly to the conditional expected value $E(A \mid a>\beta)$;

- the shift parameter $b$ set as a threshold level decreases the number of low flow events (its connection to the other threshold level $Q_{L}$ used for low flow indices definition is only indirect) and because of estimation aspects cannot grow too high.

Practically, these conclusions are the basis of the method of UGPD unknown parameters estimation. For a given shift parameter $b$ the two remaining parameters can be estimated by using the maximum likelihood method. Then estimators satisfying the above conditions have to be chosen. The linear increment of the conditional expected values suggests that the estimator $\hat{b}$ can be fixed by minimizing the mean square error. This approach has been applied to daily streamflow by Hisdal et al. (2002), Engeland et al. (2004) or Jakubowski (2005). The results show difficulties in proper estimation of the shift parameter $b$. For some low flow examples fitting the observed annual or seasonal maximum drought indices into estimated UGPD is not satisfactory. They are often distinctly worse than those obtained by the Zelenhasic and Salvai (1987) method.

HESSD

3, 859-893, 2006

Bivariate distribution of the low flow extremes estimation

W. Jakubowski

Title Page

Abstract Introduction

Conclusions

Tables References

Figures

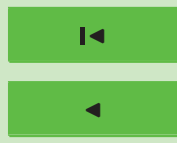

$\rightarrow$

Back

Close

Full Screen / Esc

Printer-friendly Version

Interactive Discussion 


\section{Dependence between low flow indices}

The defined above low flow indices of deficit amounts and durations are strictly dependent on one another. An example of this dependency is presented in Fig. 2. For extracting low flow events all the daily runoffs from the years 1966-2003 of the profile

5 Cigacice on the Odra River is considered. The threshold level $Q_{L}$ is put at $70 \%$ the other restriction parameters are set as follows:

- fractional coefficient $\alpha=0,005$;

- minimum drought duration - 5 days;

- drought separating interval duration - 3 days.

10 In Fig. 2 the asterisks denote the observed annual deficit or duration maximums, the crosses denote the other significant droughts. One can notice, especially for small low flows, that the dependence between these two indices is not linear. Along with the increase of the low flow durations the tendency of growing deficit increasing becomes even stronger. It seems that these nonlinear tendencies are the cause of the difficulties in estimating of the one-dimensional indices distribution.

\section{Bivariate Generalized Pareto Distribution}

\subsection{Definition}

Let $\left\{A_{i}^{(1)}, A_{i}^{(2)}\right\}_{i=1, \ldots, n}$ be a sequence of mutually independent identically distributed random variables with distribution function $F(x, t)$. Define as in the one-dimensional

Bivariate distribution of the low flow extremes estimation

W. Jakubowski

Title Page

Abstract Introduction

Conclusions References

Tables Figures

14 I

4

Back

Close

Full Screen / Esc

Printer-friendly Version

Interactive Discussion 
the limit

$$
\lim _{n \rightarrow \infty} \operatorname{Pr}\left(\frac{M_{n}^{(1)}-b_{n}^{(1)}}{a_{n}^{(1)}} \leq x, \frac{M_{n}^{(2)}-b_{n}^{(2)}}{a_{n}^{(2)}} \leq t\right)=G(x, t)
$$

HESSD

3, 859-893, 2006

Bivariate distribution of the low flow extremes estimation

W. Jakubowski

$H(x, t)= \begin{cases}1-\bar{H}(x, t), & \text { where } x, t>0, \\ 0, & \text { otherwise, }\end{cases}$

for some extreme values distribution $G$ with $\left(x_{0}, t_{0}\right)$ in the support of $G$. It can be also shown by Tajvidi (1996) that

$\bar{H}(x, t)=1-H(x, t)=\operatorname{Pr}\left(\left(D_{M}, T_{M}\right) \nless(x, t)\right)=\left(\frac{\bar{F}_{d}^{p}(x)+k \bar{F}_{d}^{p / 2}(x) \bar{F}_{t}^{p / 2}(t)+\bar{F}_{t}^{p}(t)}{\bar{F}_{d}^{p}(0)+k \bar{F}_{d}^{p / 2}(0) \bar{F}_{t}^{p / 2}(0)+\bar{F}_{t}^{p}(0)}\right)^{\frac{1}{p}}$,

$\bar{F}_{d}(x)=\left(1-\alpha_{d} k_{d}\left(b_{d}+x\right)\right)^{1 / \kappa_{d}}, \quad \bar{F}_{t}(t)=\left(1-\alpha_{t} \kappa_{t}\left(b_{t}+t\right)\right)^{1 / k_{t}}$,

Title Page

Abstract

Introduction

Conclusions

References

Tables

Figures

14

$\rightarrow 1$

4

\section{Full Screen / Esc}

Printer-friendly Version

Interactive Discussion 
5.2 Some properties of Bivariate Generalized Pareto Distribution

1. Marginal distributions of $H(x, t)$. By letting $t$ tend to infinity one can obtain

HESSD

$$
\bar{H}(x, \infty)=\operatorname{Pr}\left(D_{M}>x\right)=\frac{\bar{F}_{d}(x)}{\left(\bar{F}_{d}^{p}(0)+k \bar{F}_{d}^{p / 2}(0) \bar{F}_{t}^{p / 2}(0)+\bar{F}_{t}^{p}(0)\right)^{\frac{1}{p}}},
$$

whence the distribution $H(x, \infty)$ has a positive value (probability jump) for $x=0$. Marginal conditional probabilities

$$
\operatorname{Pr}\left(D_{M}>x+x_{0} \mid D_{M}>x_{0}\right)=\frac{\bar{H}\left(x+x_{0}, \infty\right)}{\bar{H}(x, \infty)}=\left(1-\frac{\alpha_{d}}{1-\alpha_{d} \kappa_{d}\left(b_{d}+x_{0}\right)} \kappa_{d} x\right)^{\frac{1}{\kappa_{d}}}
$$

are UGPDs with scale parameter $\alpha=\frac{\alpha_{d}}{1-\alpha_{d} \kappa_{d}\left(b_{d}+x_{0}\right)}$.

2. Conditional probability

$$
\operatorname{Pr}\left(\left(D_{M}, T_{M}\right) \leq\left(x+x_{0}, t+t_{0}\right) \mid\left(D_{M}, T_{M}\right) \leq\left(x_{0}, t_{0}\right)\right)=\frac{\bar{H}\left(x+x_{0}, t+t_{0}\right)}{\bar{H}\left(x_{0}, t_{0}\right)}
$$

is also BGPD with shift parameters $b_{d}+x_{0}$ and $b_{t}+t_{0}$.

3. Support of $H(x, t)$. Positive shift parameters $b_{d}$ and $b_{t}$ (in Fig. 3 checked as simple perpendicular lines) divide a BGPD domain of researched maximums $\left(x_{M}, t_{M}\right) \in R_{+}^{2}$ into four areas $-A, B, C, Z$. Points

- with $x_{M} \geq b_{d}$ and $t_{M} \geq b_{t}$, (A - area) obviously belong to the domain;

- with $x_{M}<b_{d}$ and $t_{M}>b_{t}\left(B-\right.$ area) or $x_{M}>b_{d}$ and $t_{M}<b_{t}(C-$ area) are projected on the straight lines $x_{M}=b_{d}$ or $t_{M}=b_{t}$ respectively;
Title Page

Bivariate distribution of the low flow

\section{extremes estimation}

W. Jakubowski

Abstract

Introduction

Conclusions

References

Tables

Figures

14

4

Back

Close

Full Screen / Esc

Printer-friendly Version

Interactive Discussion 
- with $x_{M} \leq b_{d}$ and $t_{M} \leq b_{t}$ do not belong to the domain ( $Z$-area).

Therefore, with the increasing of the shift parameters values, the number of events important for the low flow extreme indices estimation decreases. (Refer HESSD to Sect. 3.1.)

4. The density function of BGPD $H(x, t) x, t>0$ consists of three components: $\quad h(x, t) ; h(0, t) ; h(x, 0)$. Note that the first density function is two-dimensional, however the other two are onedimensional only with the support in the shift lines. The integrals: $\int_{0}^{\infty} \int_{0}^{\infty} h(x, t) d x d t=\frac{\bar{F}_{d}(0)+\bar{F}_{t}(0)}{V}-1, \quad \int_{0}^{\infty} h(x, 0) d x=1-\frac{\bar{F}_{t}(0)}{V}, \quad \int_{0}^{\infty} h(0, t) d t=1-\frac{\bar{F}_{d}(0)}{V}$, where

$V=\left(\bar{F}_{d}^{p}(0)+k \bar{F}_{d}^{\frac{p}{2}}(0) \bar{F}_{t}^{\frac{p}{2}}(0)+\bar{F}_{t}^{p}(0)\right)^{\frac{1}{p}}$,

give the probability mass of each of the areas.

5. Correlation coefficient of BGPD (for precise formulas see Appendix A). It value is calculated for the area $A$ only, and it will be apply below for the estimation of the shift parameters. Using the standard methods one obtains:

$E D_{M}=\int_{0}^{\infty} \int_{0}^{\infty} x h(x, t) d x d t, \quad$ for $k_{d} \in(-1 ; 0)$

$E D_{M}^{2}=\int_{0}^{\infty} \int_{0}^{\infty} x^{2} h(x, t) d x d t, \quad$ for $k_{d} \in\left(-\frac{1}{2} ; 0\right)$,

$E D_{M} T_{M}=\int_{0}^{\infty} \int_{0}^{\infty} x t h(x, t) d x d t, \quad$ for $k_{d}+\kappa_{t} \in(-1,0)$,

where $h(x, y)$ is the two-dimensional probability density function of $H(x, y)$. The above expected values depend on UGPDs: $\bar{F}_{d}, \bar{F}_{t}$ and integrals

Printer-friendly Version

Bivariate distribution of the low flow extremes estimation

W. Jakubowski

Title Page

Abstract

Introduction

Conclusions

References

Tables

Figures

14

I

4

Back

Close

Full Screen / Esc

Interactive Discussion 
$\int_{0}^{\alpha}\left(1+k t+t^{2}\right)^{\beta} t^{\gamma} d t$. The moments $E T_{M}, E T_{M}^{2}$ can be calculated similarly to $E D_{M}$, ED $D_{M}^{2}$. It means that the correlation coefficient exists for the parameters $\kappa_{d}, K_{t} \in\left(-\frac{1}{2} ; 0\right)$ only.

HESSD

3, 859-893, 2006

Bivariate distribution of the low flow extremes estimation

W. Jakubowski

Estimation is performed for two-dimensional observations of low flow deficits and durations. To estimate the distributions of extreme indices the above defined BGPD (Eq. 9) is applied. As it can be seen above, the BGPD depends on eight parameters. Six of them are connected with two 3-parameter UPGDs. The final two $p, k$ are related to the 10 form of the two-dimensional formula (Eq. 9). For the estimation the following method is applied:

1. For a given pair of shift parameters $b_{d}, b_{t}$ the four of them $\left(\hat{\alpha}_{d}, \hat{\kappa}_{d}, \hat{\alpha}_{t}, \hat{k}_{t}\right)$ are estimated by the maximum likelihood method, for each of the one-dimensional indices separately. Each sequence of the index observations is decreased by a shift parameter then the standard maximum likelihood method is applied. The goodness of fit for each of the UPGDs is achieved by using the chi-square test. To return to the initial values the estimated UGPD $\hat{\alpha}$ parameter is converted to $\hat{\alpha}^{\prime}$ using the conditional probability formula (Eq. 5). For further estimation the pairs of the shift parameters which do not reject the goodness of fit tests are considered only. The two last $\hat{p}, \hat{k}$ are estimated by the BGPD using the maximum likelihood method as well. The chosen shift parameters sequences are equal to the successive ordered low flow deficits and durations.

2. The best shift pair $\left(b_{d}, b_{t}\right)$ is chosen by the maximization of the correlation coefficient. This assumption is made because of the non-homogeneity of observed

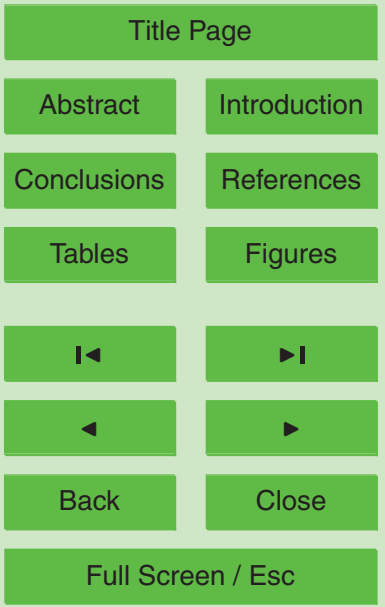

Printer-friendly Version

Interactive Discussion 
low flows. Upon observation, it is suffice to analyse the nonlinear dependence between deficit amounts and durations (for instance see Fig. 2 above). Along with the increase of the deficit duration the volumes grow much quicker - this is clearly visible for short durations. By taking the maximum correlation coefficient the homogeneity of processed low flow observations is stabilized. To determine the correlation coefficient the integrals $\int_{0}^{\alpha}\left(1+k t+t^{2}\right)^{\beta} t^{\gamma} d t$ should be computed (see Appendix A). The Gauss-Jacobi quadrature method is applied. All computations are carried out for shift pairs with connected estimators $\hat{k}_{d}, \hat{k}_{t}$ in the interval $(-0.5 ; 0)$ only. Other pairs, where at least one $\hat{k}$ stays outside the interval $(-0.5 ; 0)$, are omitted.

3. The goodness of fit of the estimated one-dimensional marginal distributions of extreme annual or seasonal index extremes is obtained by $\lambda$-Kolmogorov goodness of fit test.

\subsection{Application of BGPD for determining the probabilities of low flow extremes indices}

15 For the presentation of the above estimation method four catchments are chosen. The first catchment - about 40 thousands $\mathrm{km}^{2}$ on the Odra River (Cigacice gauges) is situated in the Polish Lowland. The second, is a small $\left(50 \mathrm{~km}^{2}\right)$ Sudety Mountains catchment - Międzylesie profile on the Nysa Klodzka River. The third, is a New Zealand highland catchment Kuripapango on the Ngaruroro River $\left(370 \mathrm{~km}^{2}\right)$ and the last one Colwick, UK, on the Trent River (about $7500 \mathrm{~km}^{2}$ ). For profiles Cigacice ${ }^{2}$, Colwick and Kuripapango all daily observed runoffs are taken into consideration. For Międzylesie, however only the summer (May-October) daily runoffs are considered. The annual average precipitation is varying from $580 \mathrm{~mm}$ (Cigacice) to over $2000 \mathrm{~mm}$ at Kuripapango.

\footnotetext{
${ }^{2}$ Polish daily runoff data are obtained from Institute of Meteorology and Water Management Wroclaw Branch, Poland, other from assembled by the ASTHyDA project Global Data Set.
}

HESSD

3, 859-893, 2006

Bivariate distribution of the low flow extremes estimation

W. Jakubowski

Title Page

Abstract

Introduction

Conclusions

Tables

References

Figures

14

4

Back

Close

Full Screen / Esc

Printer-friendly Version

Interactive Discussion 
For the two remaining profiles the average precipitation amount to $760 \mathrm{~mm}$ (Colwick) and $870 \mathrm{~mm}$ (Międzylesie).

Using the threshold level method with the Zelenhasic and Salvai restrictions the observed low flow deficit amounts and durations are extracted. The threshold level is set 5 at $Q_{70 \%}$, minimum drought duration is put at 5 days, separation criteria at 3 days and the coefficient $\alpha$ is set at 0.005 . The estimated best pairs of shift parameters $\left(b_{d}, b_{t}\right)$ and the correlation coefficients are shown in Table 1.

The estimation results are shown in Figs. 4-7. They present estimated twodimensional probability plots of extreme low flow deficit amounts and durations. As 10 in Fig. 2 asterisks denote the observed annual or summer maximums of deficits or durations, crosses refer to other significant observed droughts. Straight lines depict the estimated best shift parameters. The quantile curves - constant value probability lines determine the areas laying left or below them whose estimated probabilities of non-exceedance (Eq. 9) are equal to 50, 80, 90 and 95\%.

15 Note that shift lines are generally dividing the observed low flow events in two classes. The first one (in Fig. 3 denoted as $Z$-area) consists of many small insignificant low flows. The deficit amount is slower in its increase depending on their duration. The second one (in Fig. $3 A$-area) contains smaller number of greater low flows with quicker deficit amount increasing. Such a difference confirms the earlier assumed non-homogeneity of the observed low flows. Practically, it means that these smaller low flows are caused by other hydrological processes than the greater ones. Because of few observed events, the two remaining areas $(B, C)$ are exerting a small influence on the bivariate probability behaviour.

Considered above non-homogeneity is observable in the graphs of the quantile 25 curves similarly. Especially for lower probabilities (in figures for $\operatorname{Pr}=50 \%$ ), they tend to be moved to the left. This theoretically causes the lowering of the estimated duration quantiles. As it can be seen below, this effect does not transmit to the marginal distributions, so for further calculation it is not taken into consideration.

Taking the marginal distributions (Eq. 11) of the estimated BGPD one can compute

HESSD

3, 859-893, 2006

\section{Bivariate distribution of the low flow extremes estimation}

W. Jakubowski

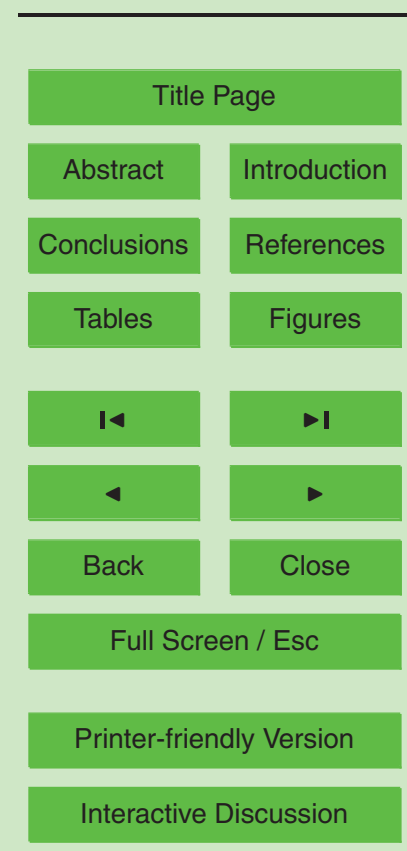

EGU 
the probability of each of the examined maximum values of the indices. In Figs. 8-11 the probabilities of the non-exceedance of the low flow extreme deficit amounts and durations are presented. Because of the positive probability values of the marginal distribution $\left.H(x, \infty)\right|_{x=0}$ and $\left.H(\infty, t)\right|_{t=0}$ the one-dimensional distributions of low flow 5 indices have a discontinuous probability jump set at the estimated shift parameter. These jumps, as it was shown in Eq. (11), depend on behaviour of the both researched indices. And of course they are distinctly lowering the probabilities values obtained by the investigation of the UGPD only. We note that the probability jumps of the deficit amount are laying much lower than the respective probabilities for the low flow duraflow indices.

Goodness of the fitting into the marginal BGPDs are achieved by making use of the $\lambda$-Kolmogorov test. The results are shown in Table 2. Hypotheses of the goodness of fit are not rejected at any of the investigated cases.

\subsection{Comparison to Zelenhasić and Salvai (1987) model (ZS model)}

For the determination of the probabilities of maximum low flow indices by Zelenhasic and Salvai model the formulae

$G(x)=\operatorname{Pr}(E=0)+\sum_{k=1}^{\infty} F^{k}(x) \operatorname{Pr}(E=k)$

is applied, where the probabilities are estimated for annual or seasonal data and

- $G(x)$ is a searched distribution function of maximum low flow indices;

$-E$ is an estimated number of low events in the season;

- $F(x)$ is an estimated distribution function of the low flow indices.

The Figs. 12-15 show the differences between the results. A tendency to overestimate quantiles in ZS model (NIZOWKA program - Jakubowski and Radczuk, 2004)
HESSD

3, 859-893, 2006

Bivariate distribution of the low flow extremes estimation

W. Jakubowski

Title Page

Abstract

Introduction

Conclusions

Tables

References

Figures

14

4

Back

Close

Full Screen / Esc

Printer-friendly Version

Interactive Discussion 
is observed, especially for high probabilities of non-exceedance. Only in the case of the Cigacice profile the probability of the observed maximum indices (low flow deficit amount) is nearly equal in the both methods of estimation. All other indices show lower probabilities of the non-exceedance. It means that ZS model permits too high low flow 5 threat than it is in reality.

\section{Conclusions}

1. The proposed Bivariate Generalized Pareto Distribution fits very well in the observed shifted extremes of the low flow indices (deficit and duration). The only problem of the estimation are the lower than -0.5 values of $\hat{k}_{d}$ estimator. There are some profiles where $\hat{\kappa}_{d}$ is always lower then -1 . This tendency is not observable for the $\hat{\kappa}_{t}$ estimator.

2. Because of the high values of shift parameters (in all researched cases) the observed low flows show distinct statistical non-homogeneity. It means that the different hydrological processes results in the arising of the huge and minor low flows.

3. The estimated correlation between two low flow indices (deficit amount and duration) is very high - in each case it oversteps 0.9 . This is why the distribution estimation of the extremes of the low flow indices should not be considered alone one from another.

4. Some of profiles show substantial seasonal non-homogeneity.

\section{HESSD}

3, 859-893, 2006

Bivariate distribution of the low flow

extremes estimation

W. Jakubowski

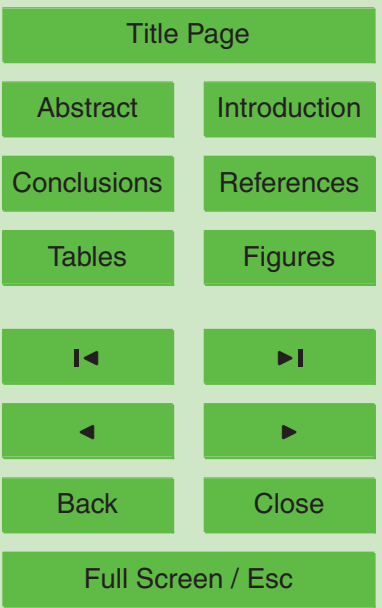

Printer-friendly Version

Interactive Discussion 


\section{Appendix A}

\section{Expected values of BGPD}

\section{HESSD}

1. First moment:

$$
\begin{aligned}
& E D_{M}=\int_{0}^{\infty} \int_{0}^{\infty} x h(x, t) d x d t=\frac{1-\alpha_{d} k_{d}}{\alpha_{d} \kappa_{d}}\left(\frac{\bar{F}_{d}(0)+\bar{F}_{t}(0)}{V}-1\right) \\
& +\frac{k(2-p)}{2 V p \alpha_{d} \kappa_{d}\left(1+\kappa_{d}\right)}\left\{\bar{F}_{d}^{1+\kappa_{d}}(0) /\left(\frac{\bar{F}_{t}^{\frac{p}{2}}(0)}{\bar{F}_{d}^{\frac{p}{2}}(0)}, \frac{1}{p}-1,0\right)+\bar{F}_{t}^{1+\kappa_{d}}(0) /\left(\frac{\bar{F}_{d}^{\frac{p}{2}}(0)}{\bar{F}_{t}^{\frac{p}{2}}(0)}, \frac{1}{p}-1, \frac{2 \kappa_{d}}{p}\right)\right\} \\
& +\frac{\left(4-k^{2}\right)(1-p)}{2 V p \alpha_{d} \kappa_{d}\left(1+\kappa_{d}\right)}\left\{\bar{F}_{d}^{1+\kappa_{d}}(0) /\left(\frac{\bar{F}_{t}^{\frac{p}{2}}(0)}{\bar{F}_{d}^{\frac{p}{2}}(0)}, \frac{1}{p}-2,1\right)+\bar{F}_{t}^{1+\kappa_{d}}(0) /\left(\frac{\bar{F}_{d}^{\frac{p}{2}}(0)}{\bar{F}_{t}^{\frac{p}{2}}(0)}, \frac{1}{p}-2, \frac{2 \kappa_{d}}{p}+1\right)\right\} .
\end{aligned}
$$

3, 859-893, 2006

\section{Bivariate distribution} of the low flow

\section{extremes estimation}

W. Jakubowski

Title Page

The first moment is finite when $k_{d} \in(-1 ; 0)$.

2. Second moment

$$
\begin{aligned}
& E D_{M}^{2}=\int_{0}^{\infty} \int_{0}^{\infty} x^{2} h(x, t) d x d t=\left(\frac{1-\alpha_{d} \kappa_{d}}{\alpha_{d} \kappa_{d}}\right)^{2}\left(\frac{\bar{F}_{d}(0)+\bar{F}_{t}(0)}{V}-1\right) \\
& +\frac{\left(1-\alpha_{d} \kappa_{d}\right) k(2-p)}{V p \alpha_{d}^{2} k_{d}^{2}\left(1+\kappa_{d}\right)}\left\{\bar{F}_{d}^{1+\kappa_{d}}(0) /\left(\frac{\bar{F}_{t}^{\frac{p}{2}}(0)}{\bar{F}_{d}^{\frac{p}{2}}(0)}, \frac{1}{p}-1,0\right)+\bar{F}_{t}^{1+\kappa_{d}}(0) /\left(\frac{\bar{F}_{d}^{\frac{p}{2}}(0)}{\bar{F}_{t}^{\frac{p}{2}}(0)}, \frac{1}{p}-1, \frac{2 \kappa_{d}}{p}\right)\right\}
\end{aligned}
$$

14

4

Back
$>$ I

\section{Full Screen / Esc}

Printer-friendly Version 


$$
\begin{aligned}
& +\frac{\left(1-\alpha_{d} \kappa_{d}\right)\left(4-k^{2}\right)(1-p)}{V p \alpha_{d}^{2} \kappa_{d}^{2}\left(1+\kappa_{d}\right)}\left\{\bar{F}_{d}^{1+\kappa_{d}}(0) /\left(\frac{\bar{F}_{t}^{\frac{p}{2}}(0)}{\bar{F}_{d}^{\frac{p}{2}}(0)}, \frac{1}{p}-2,1\right)\right. \\
& \left.+\bar{F}_{t}^{1+\kappa_{d}}(0) /\left(\frac{\bar{F}_{d}^{\frac{p}{2}}(0)}{\bar{F}_{t}^{\frac{p}{2}}(0)}, \frac{1}{p}-2, \frac{2 \kappa_{d}}{p}+1\right)\right\} \\
& -\frac{k(2-p)}{2 V p \alpha_{d}^{2} k_{d}^{2}\left(1+2 \kappa_{d}\right)}\left\{\bar{F}_{d}^{1+2 \kappa_{d}}(0) /\left(\frac{\bar{F}_{t}^{\frac{p}{2}}(0)}{\bar{F}_{d}^{\frac{p}{2}}(0)}, \frac{1}{p}-1,0\right)\right. \\
& \left.+\bar{F}_{t}^{1+2 \kappa_{d}}(0) /\left(\frac{\bar{F}_{d}^{\frac{p}{2}}(0)}{\bar{F}_{t}^{\frac{p}{2}}(0)}, \frac{1}{p}-1, \frac{4 \kappa_{d}}{p}\right)\right\} \\
& +\frac{\left(4-k^{2}\right)(1-p)}{2 V p \alpha_{d}^{2} k_{d}^{2}\left(1+2 \kappa_{d}\right)}\left\{\bar{F}_{d}^{1+2 \kappa_{d}}(0) /\left(\frac{\bar{F}_{t}^{\frac{p}{2}}(0)}{\bar{F}_{d}^{\frac{p}{2}}(0)}, \frac{1}{p}-2,1\right)\right. \\
& \left.+\bar{F}_{t}^{1+2 \kappa_{d}}(0) /\left(\frac{\bar{F}_{d}^{\frac{p}{2}}(0)}{\bar{F}_{t}^{\frac{p}{2}}(0)}, \frac{1}{p}-2, \frac{4 \kappa_{d}}{p}+1\right)\right\} .
\end{aligned}
$$

\section{HESSD}

3, 859-893, 2006

\section{Bivariate distribution} of the low flow extremes estimation

W. Jakubowski

Title Page

Abstract

Introduction

Conclusions

References

Tables

Figures

14

4

Back

Close

Full Screen / Esc

Printer-friendly Version

Interactive Discussion

The second moment is finite when $k_{d} \in\left(-\frac{1}{2} ; 0\right)$. 
3. Mixed moment

$$
\begin{aligned}
E D_{M} T_{M} & =\int_{0}^{\infty} \int_{0}^{\infty} x t h(x, t) d x d t=\frac{1-\alpha_{t} \kappa_{t}}{\alpha_{t} \kappa_{t}} E D_{M}+\frac{1-\alpha_{d} \kappa_{d}}{\alpha_{d} \kappa_{d}} E T_{M} \\
& -\frac{1-\alpha_{t} \kappa_{t}}{\alpha_{t} \kappa_{t}} \frac{1-\alpha_{d} \kappa_{d}}{\alpha_{d} \kappa_{d}}\left(\frac{\bar{F}_{d}(0)+\bar{F}_{t}(0)}{V}-1\right) \\
& -\frac{k(2-p)}{2 V p \alpha_{d} \kappa_{d} \alpha_{t} \kappa_{t}\left(1+\kappa_{d}+\kappa_{t}\right)}\left\{\bar{F}_{d}^{1+\kappa_{d}+\kappa_{t}}(0) /\left(\frac{\bar{F}_{t}^{\frac{p}{2}}(0)}{\bar{F}_{d}^{\frac{p}{2}}(0)}, \frac{1}{p}-1, \frac{2 \kappa_{t}}{p}\right)\right. \\
& \left.+\bar{F}_{t}^{1+\kappa_{d}+\kappa_{t}}(0) /\left(\frac{\bar{F}_{d}^{\frac{p}{2}}(0)}{\bar{F}_{t}^{\frac{p}{2}}(0)}, \frac{1}{p}-1, \frac{2 \kappa_{d}}{p}\right)\right\} \\
& -\frac{\left(4-k^{2}\right)(1-p)}{2 V p \alpha_{d} \kappa_{d} \alpha_{t} \kappa_{t}\left(1+\kappa_{d}+\kappa_{t}\right)}\left\{\bar{F}_{d}^{1+\kappa_{d}+\kappa_{t}}(0) /\left(\frac{\bar{F}_{t}^{\frac{p}{2}}(0)}{\bar{F}_{d}^{\frac{p}{2}}(0)}, \frac{1}{p}-2, \frac{2 \kappa_{t}}{p}+1\right)\right. \\
& \left.+\bar{F}_{t}^{1+\kappa_{d}+\kappa_{t}}(0) /\left(\frac{\bar{F}_{d}^{\frac{p}{2}}(0)}{\bar{F}_{t}^{\frac{p}{2}}(0)}, \frac{1}{p}-2, \frac{2 \kappa_{d}}{p}+1\right)\right\}
\end{aligned}
$$

HESSD

3, 859-893, 2006

\section{Bivariate distribution} of the low flow extremes estimation

W. Jakubowski

Title Page

Abstract

Introduction

Conclusions

References

Tables

Figures

14

$\rightarrow 1$

4

Back

Close

Full Screen / Esc

The mixed moment is finite when $\kappa_{d}+k_{t} \in(-1 ; 0)$.

The parameter $V$ is defined by Eq. (14) in Sect. 5.2 and the integral: $I(\alpha, \beta, \gamma)=\int_{0}^{\alpha}\left(1+k t+t^{2}\right)^{\beta} t^{\gamma} d t$. Since $\gamma>-1$, the integral $/$ is always finite.

Printer-friendly Version

Interactive Discussion

EGU 


\section{References}

Coles, S.: An Introduction to Statistical Modeling of Extreme Values, Springer-Verlag London Limited, 2001.

Engeland, K., Hisdal, H., and Frigessi, A.: Practical Extreme Value Modelling of Hydrological Floods and Droughts: A Case Study, Extremes, 7, 5-30, 2004.

Hisdal, H., Tallaksen, L. M., and Frigessi, A.: Handling non-extreme events in extreme value modelling of streamflow droughts, IAHS Publ. No 274, 281-288, 2002.

Jakubowski, W. and Radczuk, L.: Estimation of Hydrological Drought Characteristics NIZOWKA2003, software, on accompanying CD to Hydrological Drought, Processes and Estimation Methods for Streamflow and Groundwater, edited by: Tallaksen, L. M. and van Lanen, H. A. J, 2004, Elsevier, Amsterdam, 2004.

Jakubowski, W.: Zastosowanie Uogólnionego Rozkladu Pareto do wyznaczania rozkladów maksymalnych charakterystyk niżówek, ZNAR we Wroclawiu (in Polish), 520, 29-41, 2005.

Pickands, J.: Statistical inference using extreme order statistics, Ann. Statist., 3, 119-131, 1975.

Resnick, S. I.: Extreme values, Regular Variation and Point Processes, Berlin Springer-Verlag, 1987.

Tajvidi, N.: Characterisation and Some Statistical Aspects of Univariate and Multivariate Generalized Pareto Distribution, $\mathrm{PhD}$ Thesis, available at: http://www.maths.lth.se/matstat/staff/nader/fullpub.html, 1996.

Tallaksen, L. M. and van Lanen, H. A. J. (Eds.): Hydrological Drought, Processes and Estimation Methods for Streamflow and Groundwater, Elsevier, Amsterdam, 2004.

Zelenhasić, E. and Salvai, A.: A Method of Streamflow Drought Analysis, Water Resour. Res., 23(1), 156-168, 1987.

\section{HESSD}

3, 859-893, 2006

Bivariate distribution of the low flow

\section{extremes estimation}

W. Jakubowski

Title Page

Abstract

Introduction

Conclusions

References

Tables

Figures

14

Back

Close

Full Screen / Esc

Printer-friendly Version

Interactive Discussion 


\section{HESSD}

3, 859-893, 2006

\section{Bivariate distribution} of the low flow

\section{extremes estimation}

W. Jakubowski

Table 1. The best shift parameters estimated by the correlation coefficient maximization.

\begin{tabular}{|c|c|c|c|c|c|c|}
\hline \multirow{2}{*}{ Profile } & \multirow{2}{*}{$\begin{array}{l}\text { Years of } \\
\text { the observed } \\
\text { runoffs }\end{array}$} & \multicolumn{2}{|c|}{ Observed maximum of } & \multicolumn{2}{|c|}{ Shift parameter for } & \multirow{2}{*}{$\begin{array}{l}\text { Correlation } \\
\text { coefficient }\end{array}$} \\
\hline & & $\begin{array}{l}\text { deficit in } \\
\text { millions } \mathrm{m}^{3}\end{array}$ & $\begin{array}{l}\text { duration } \\
\text { in days }\end{array}$ & $\begin{array}{l}b_{d} \text {-deficit in mil- } \\
\text { lions } \mathrm{m}^{3}\end{array}$ & $\begin{array}{l}b_{t} \text {-duration in } \\
\text { days }\end{array}$ & \\
\hline Cigacice & $1966-2003$ & 1371.686 & 270 & 74.650 & 39 & 0.9312 \\
\hline Colwick & $1959-2000$ & 266.722 & 180 & 10.353 & 17 & 0.9063 \\
\hline Kuripapango & $1965-2000$ & 39.917 & 113 & 3.859 & 23 & 0.9386 \\
\hline Międzylesie & $1966-2003$ & 2.471 & 178 & 0.134 & 24 & 0.9315 \\
\hline
\end{tabular}




\section{HESSD}

3, 859-893, 2006

\section{Bivariate distribution} of the low flow

\section{extremes estimation}

W. Jakubowski

Table 2. The $\lambda$-Kolmogorov test; goodness of fit into marginal BGPD.

\begin{tabular}{|c|c|c|c|c|}
\hline Profile & \multicolumn{2}{|c|}{$\begin{array}{l}\text { Number of the low flow events } \\
\text { over shift parameters }\end{array}$} & \multicolumn{2}{|c|}{$\begin{array}{l}\lambda \text {-Kolmogorov test; } \\
\text { values for low flow }\end{array}$} \\
\hline Cigacice & 30 & 29 & 0.477 & 0.400 \\
\hline Colwick & 71 & 70 & 0.661 & 0.504 \\
\hline Kuripapango & 54 & 52 & 0.365 & 0.261 \\
\hline Międzylesie & 35 & 34 & 0.374 & 0.419 \\
\hline
\end{tabular}

Title Page

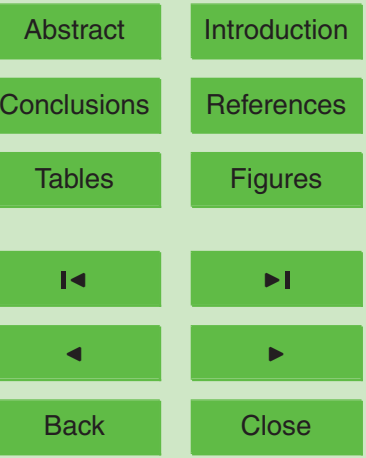

Full Screen / Esc

Printer-friendly Version

Interactive Discussion 


\section{Bivariate distribution} of the low flow

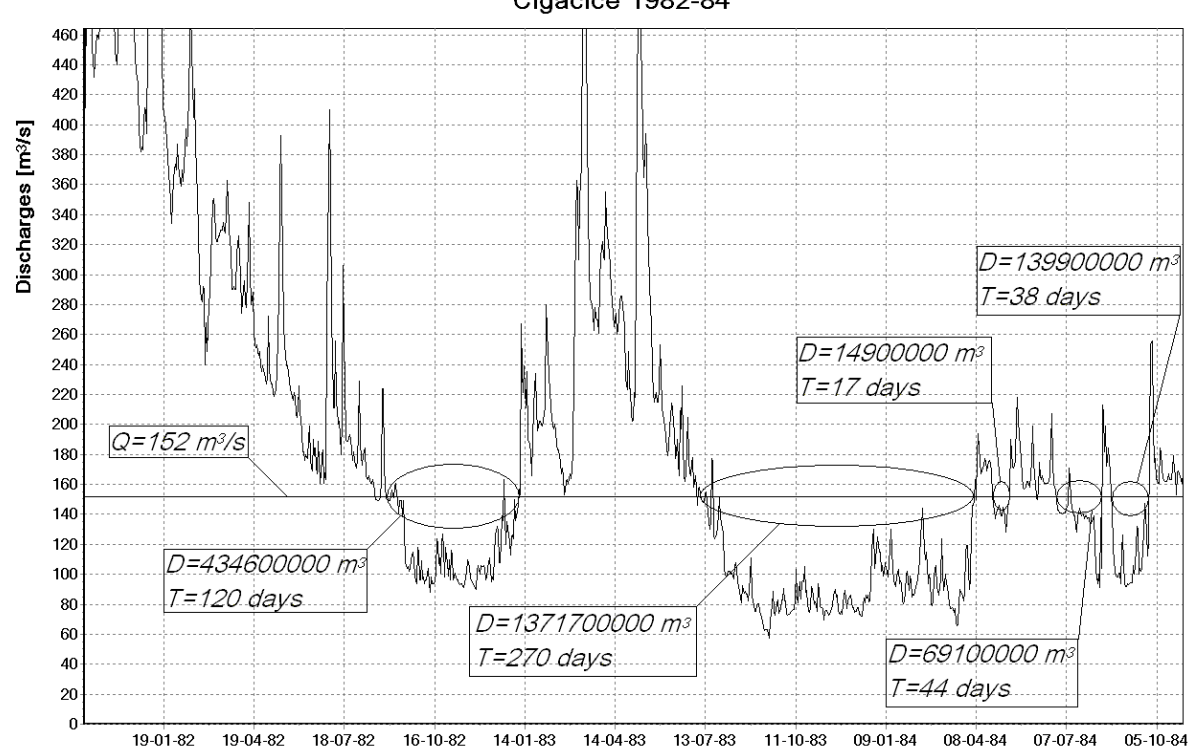

\section{extremes estimation}

W. Jakubowski

Title Page

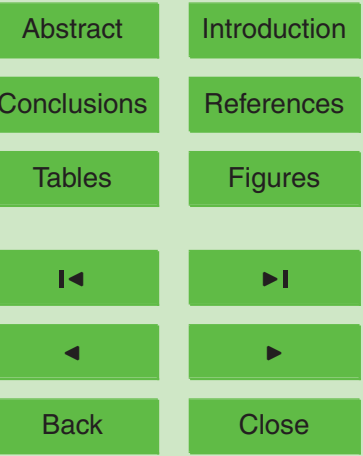

Full Screen / Esc

Fig. 1. The Odra River, Cigacice profile; an example of the low flow indices.

Printer-friendly Version

Interactive Discussion 
HESSD

3, 859-893, 2006

Bivariate distribution of the low flow

OF THE DEFICIT VOLUME AND REAL TIME (All year drougth 01-11 31-10)

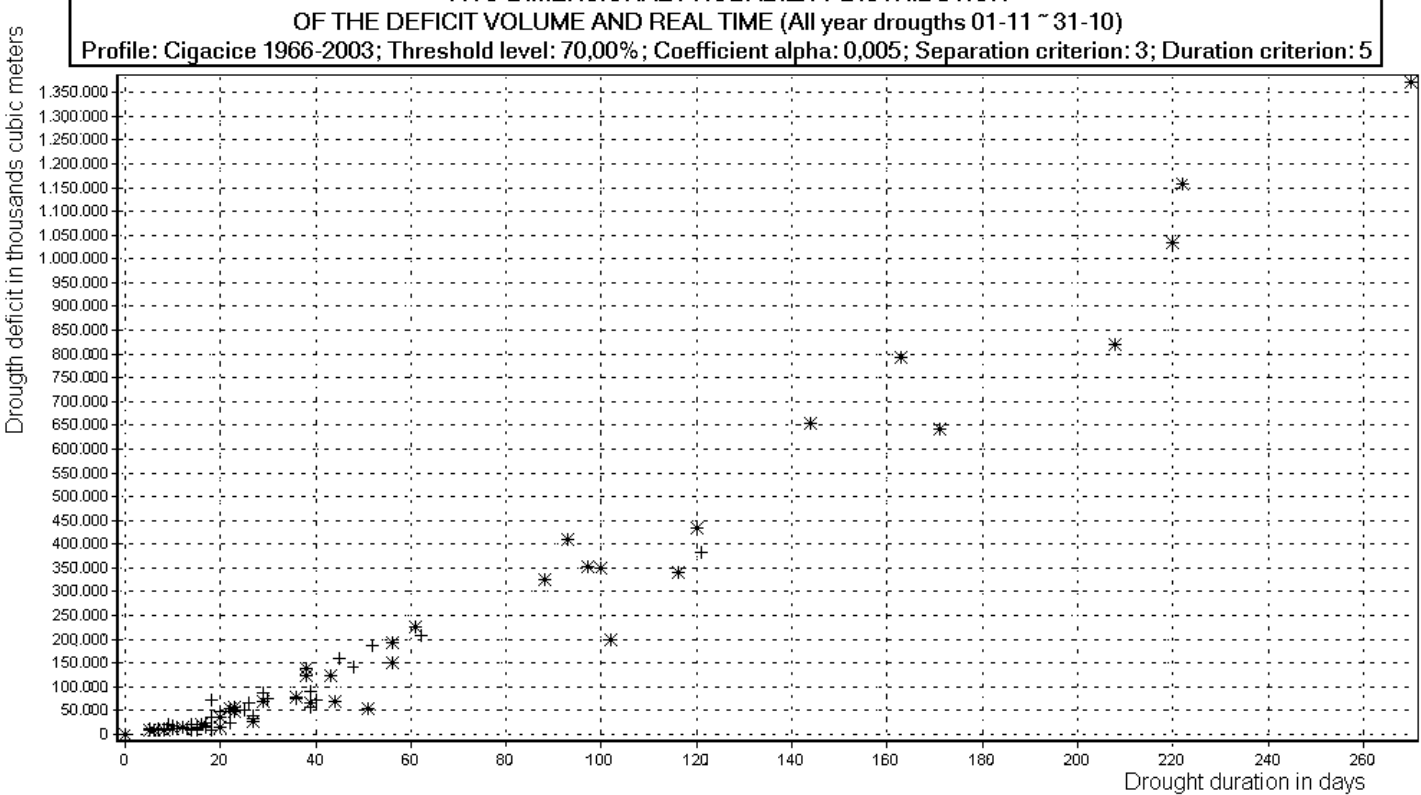

Fig. 2. The Odra River, Cigacice profile; an observed low flow deficits and durations.

\section{extremes estimation}

W. Jakubowski

Title Page

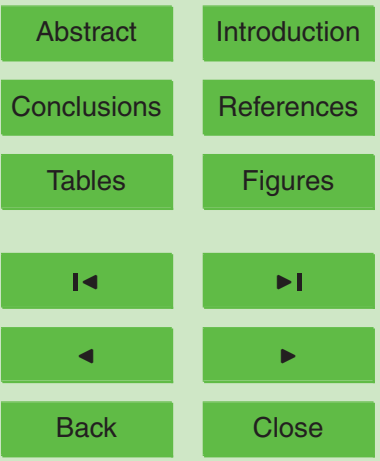

Full Screen / Esc

Printer-friendly Version

Interactive Discussion 
HESSD

3, 859-893, 2006

\section{Bivariate distribution} of the low flow

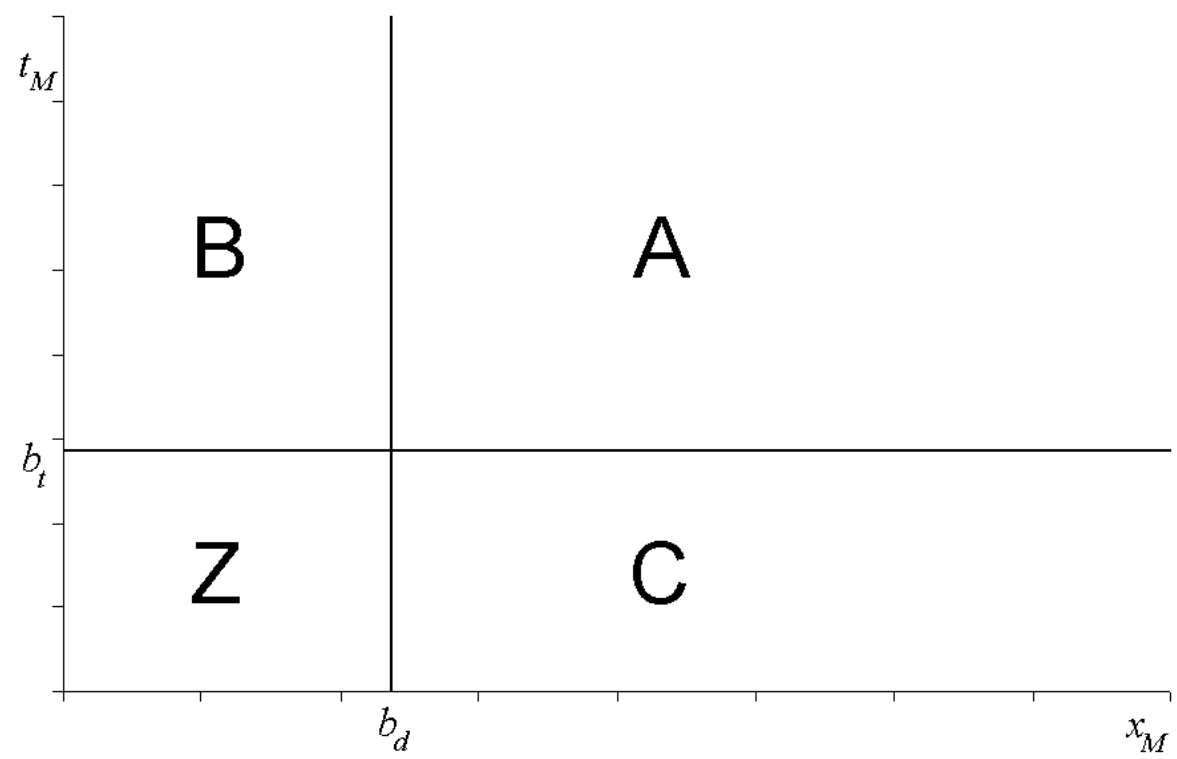

extremes estimation

W. Jakubowski

Title Page

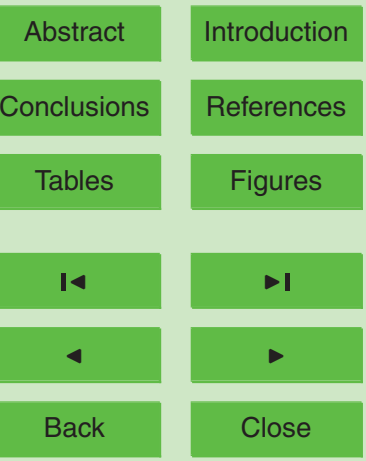

Full Screen / Esc

Printer-friendly Version

Interactive Discussion 
HESSD

3, 859-893, 2006

\section{Bivariate distribution of the low flow \\ extremes estimation}

OF THE DEFICIT VOLUME AND TOTAL TIME (All year drougths 01-11 31-10)

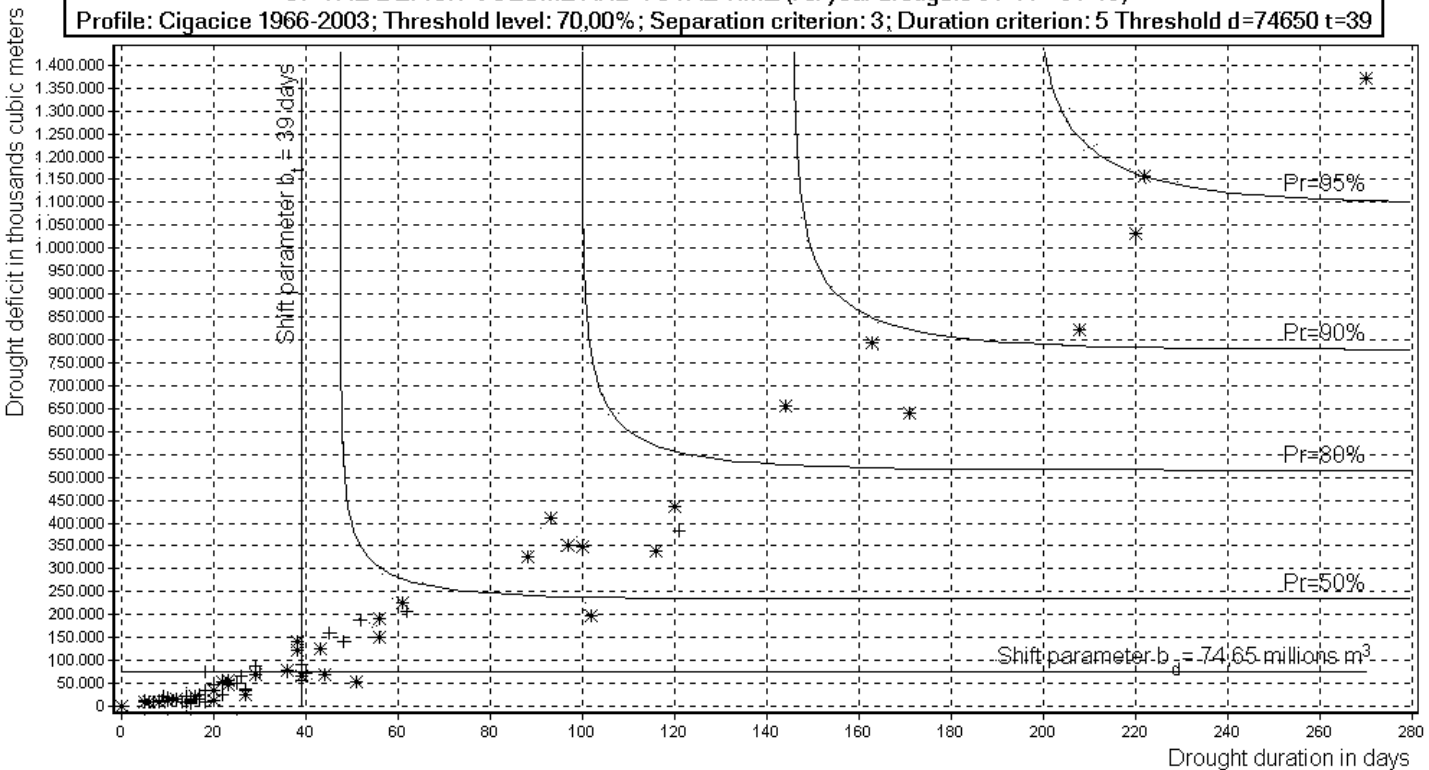

Fig. 4. The Odra River, Cigacice profile; an annual low flows - fitting into the Bivariate Generalized Pareto Distribution.
W. Jakubowski

Title Page

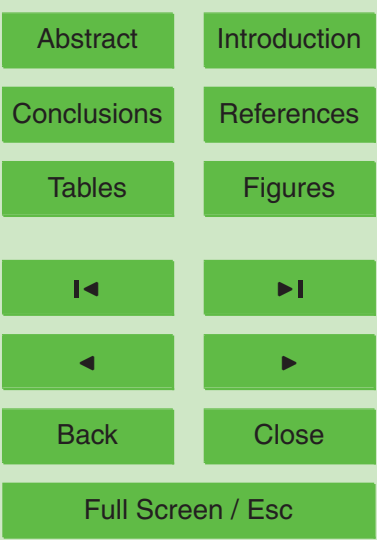

Printer-friendly Version

Interactive Discussion 
HESSD

3, 859-893, 2006

\section{Bivariate distribution of the low flow \\ extremes estimation}

OF DEFICIT VOLUME AND DURATION MAXIMUMS (All year drougths 01-11 31-10)

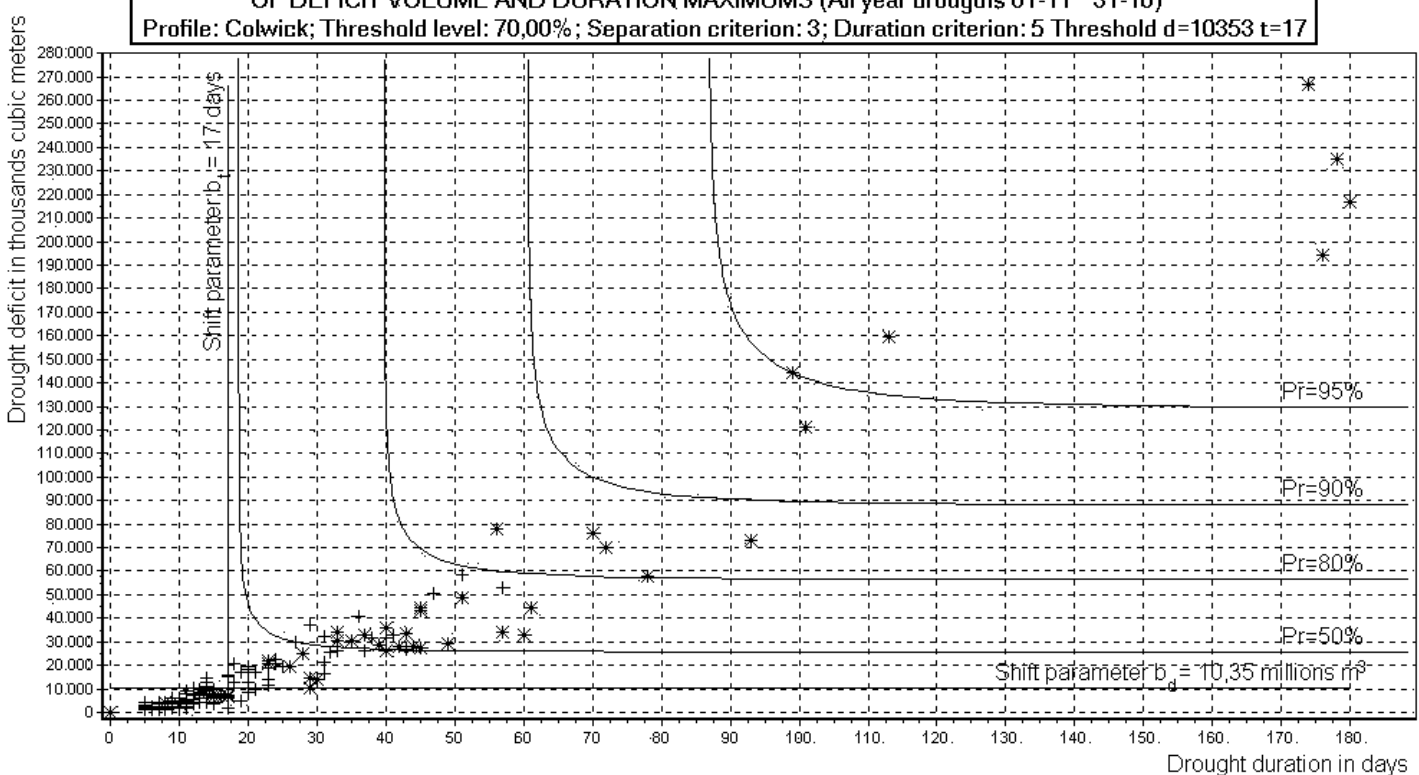

Fig. 5. The Trent River, Colwick profile; an annual low flows - fitting into the Bivariate Generalized Pareto Distribution.
W. Jakubowski

Title Page

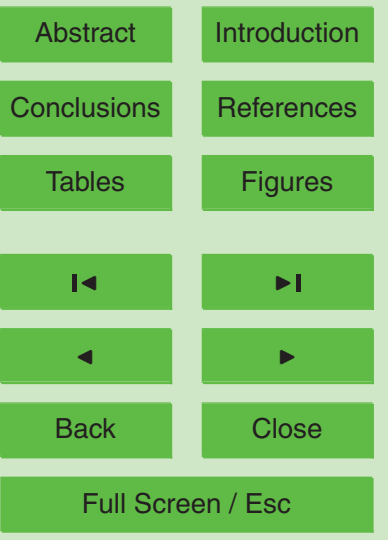

Printer-friendly Version

Interactive Discussion 
HESSD

3, 859-893, 2006

Bivariate distribution of the low flow

\section{extremes estimation}

W. Jakubowski

Title Page

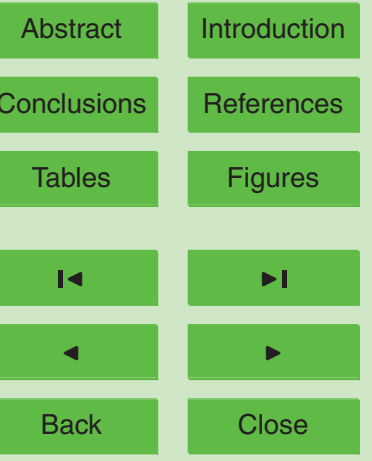

Full Screen / Esc

Printer-friendly Version

Interactive Discussion 


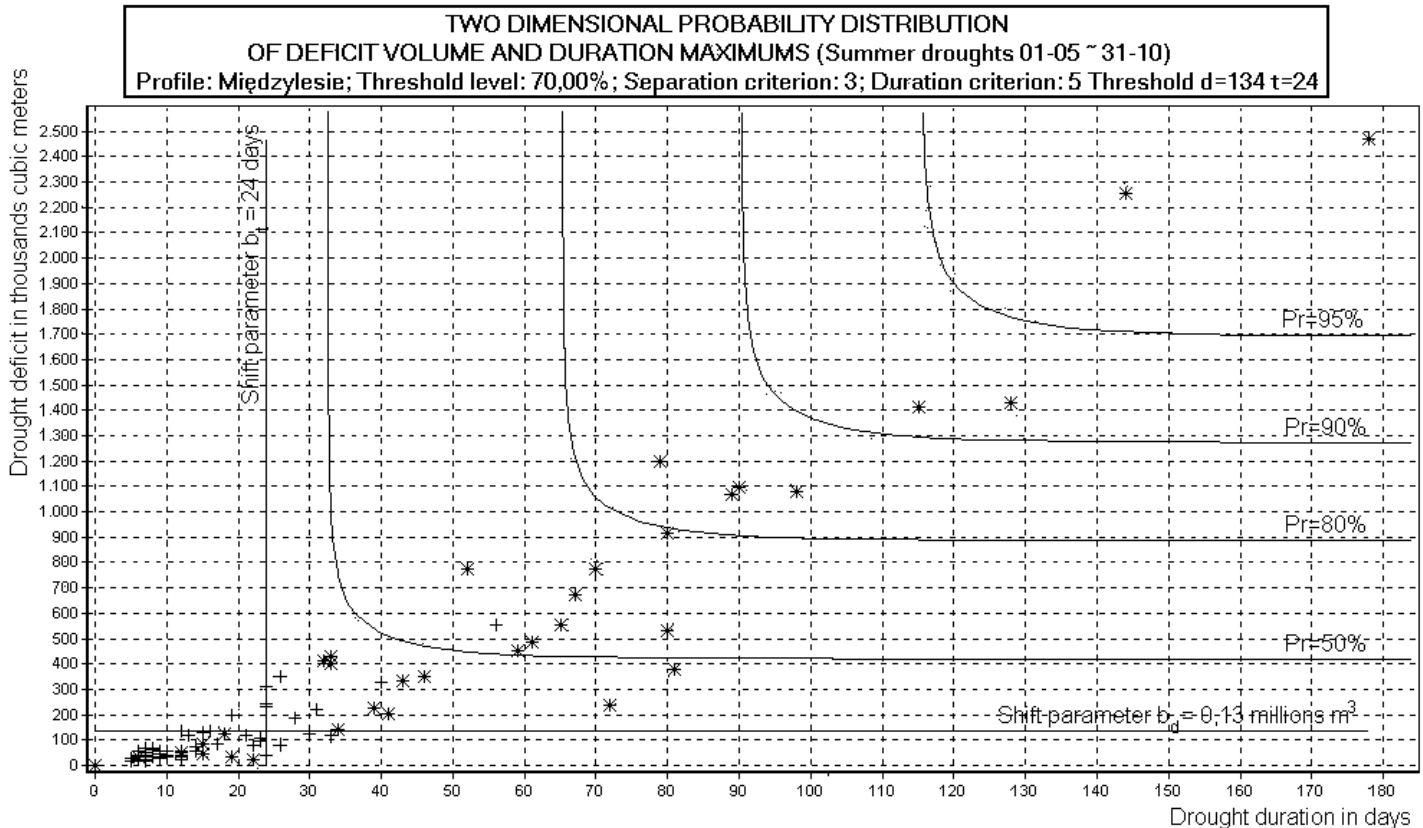

Fig. 7. The Nysa Klodzka River, Międzylesie profile; a summer low flows - fitting into the Bivariate Generalized Pareto Distribution.

\section{Bivariate distribution of the low flow \\ extremes estimation}

W. Jakubowski

Title Page

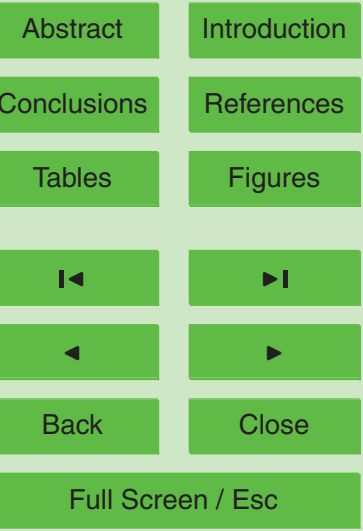

Printer-friendly Version

Interactive Discussion 


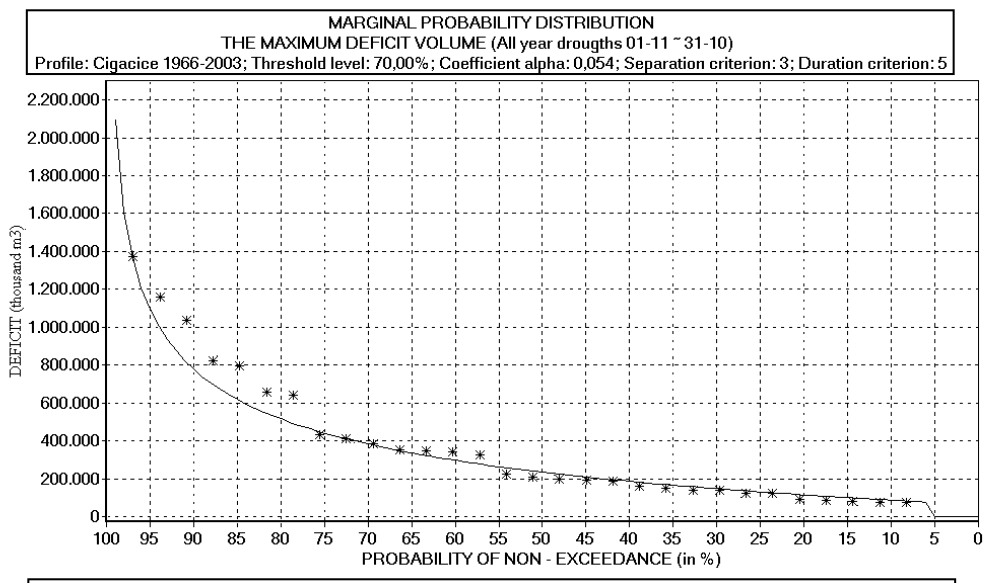

HESSD

3, 859-893, 2006

\section{Bivariate distribution of the low flow \\ extremes estimation}

W. Jakubowski

Title Page

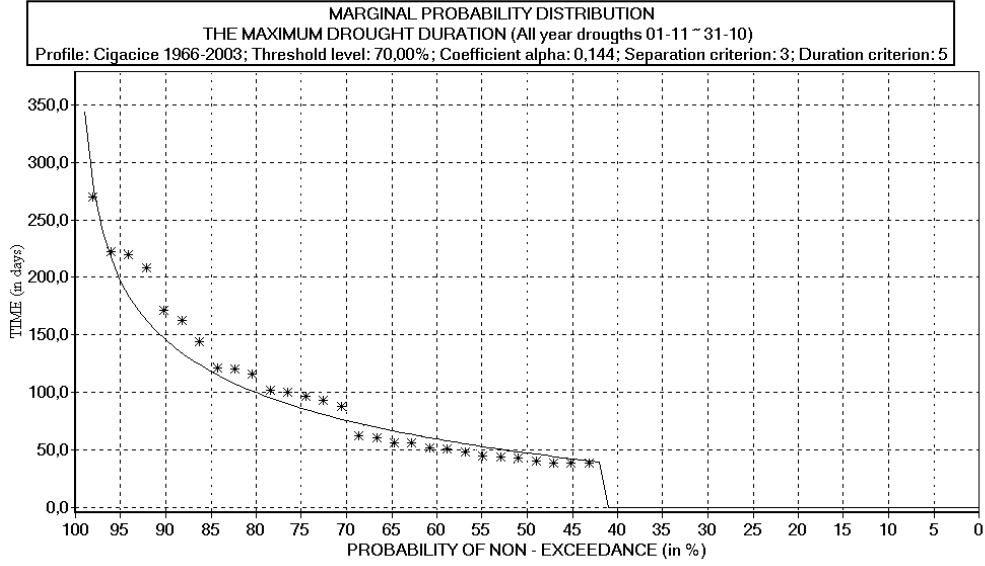

Abstract

Introduction

Conclusions

References

Tables

Figures

14

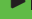

4

Back

Close

Full Screen / Esc

Printer-friendly Version

Fig. 8. The Odra River, Cigacice profile; an annual low flows - fitting into marginal distributions of the low flow maximum deficit volume and duration.

Interactive Discussion 


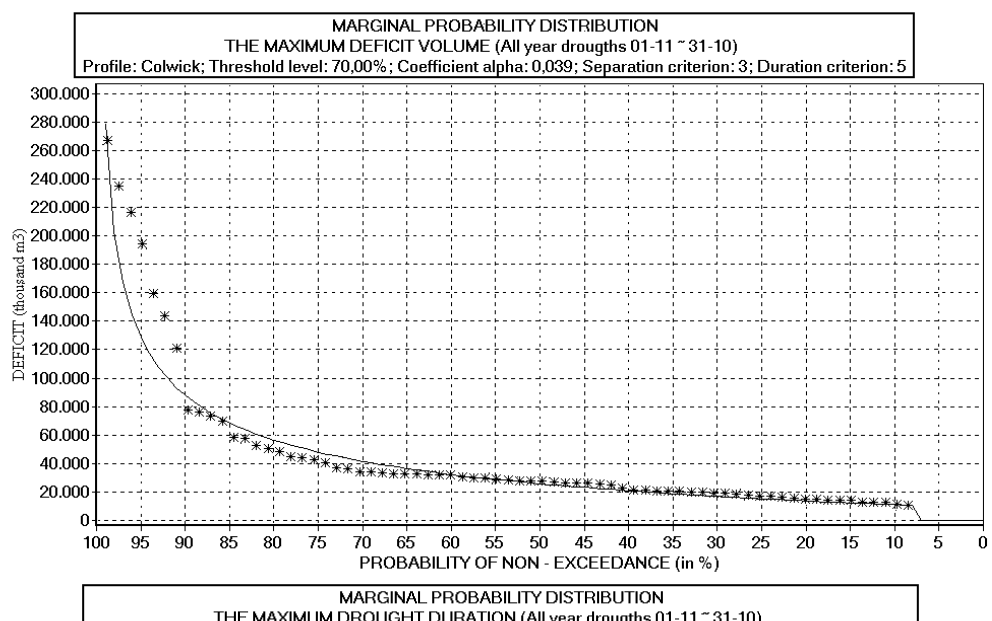

HESSD

3, 859-893, 2006

\section{Bivariate distribution of the low flow \\ extremes estimation}

W. Jakubowski

Title Page

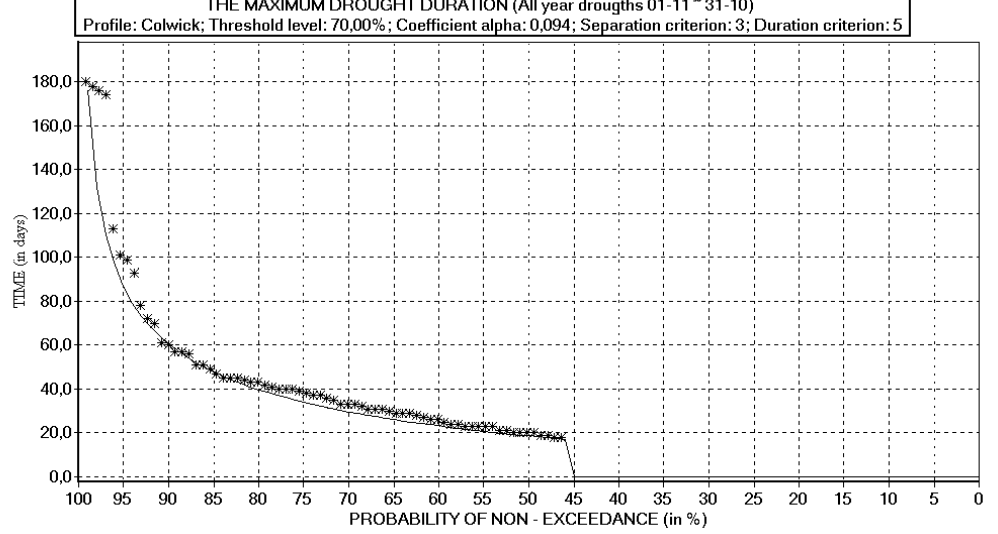

Abstract

Introduction

Conclusions

References

Tables

Figures

14

\section{I}

4

Back

Close

\section{Full Screen / Esc}

Printer-friendly Version

Fig. 9. The Trent River, Colwick profile; an annual low flows - fitting into marginal distributions of the low flow maximum deficit volume and duration.

Interactive Discussion 


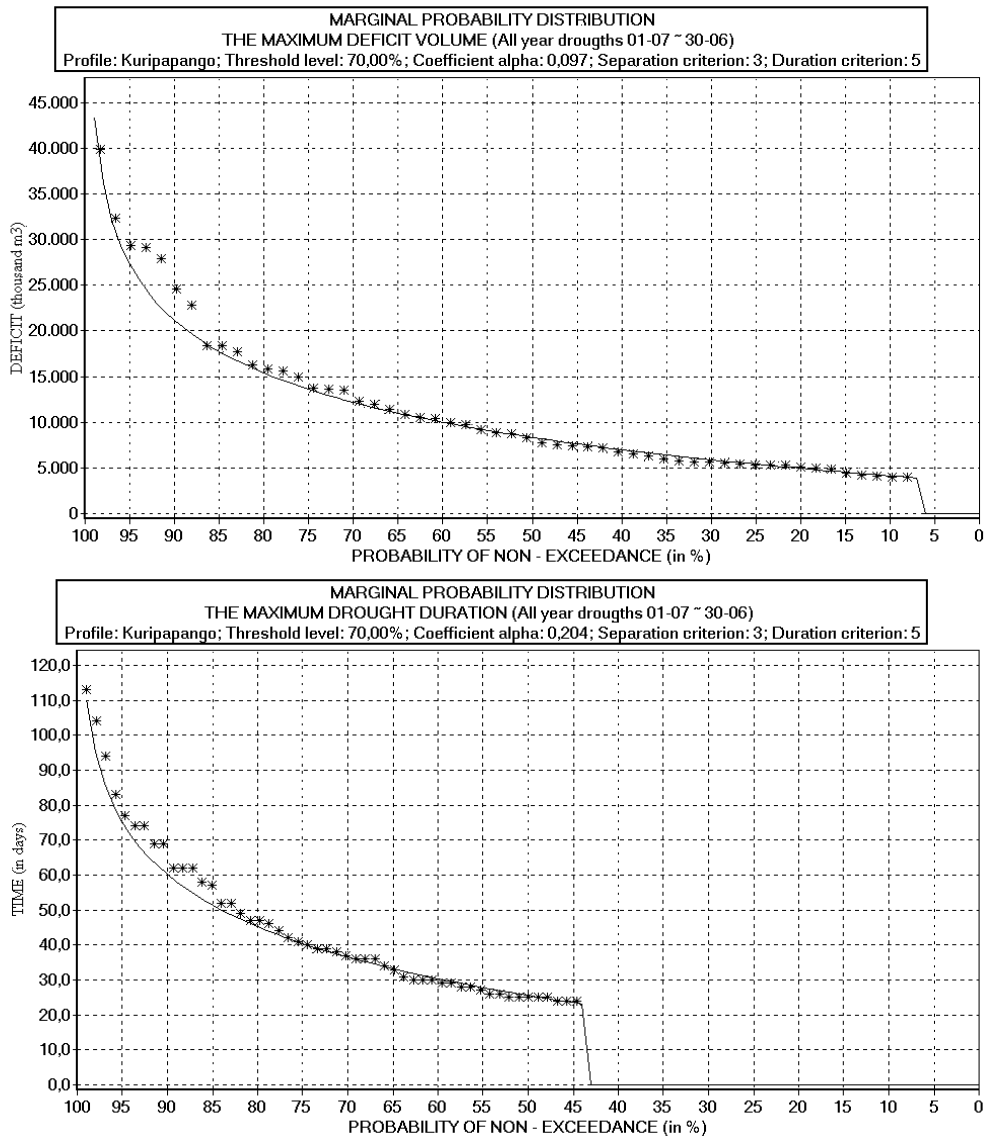

HESSD

3, 859-893, 2006

Bivariate distribution of the low flow

extremes estimation

W. Jakubowski

Title Page

Abstract

Introduction

Conclusions

References

Tables

\section{Figures}

14

\section{I}

4

Back

Close

\section{Full Screen / Esc}

Printer-friendly Version

Interactive Discussion

Fig. 10. The Ngaruroro River, Kuripapango profile; an annual low flows - fitting into marginal distributions of the low flow maximum deficit volume and duration. 


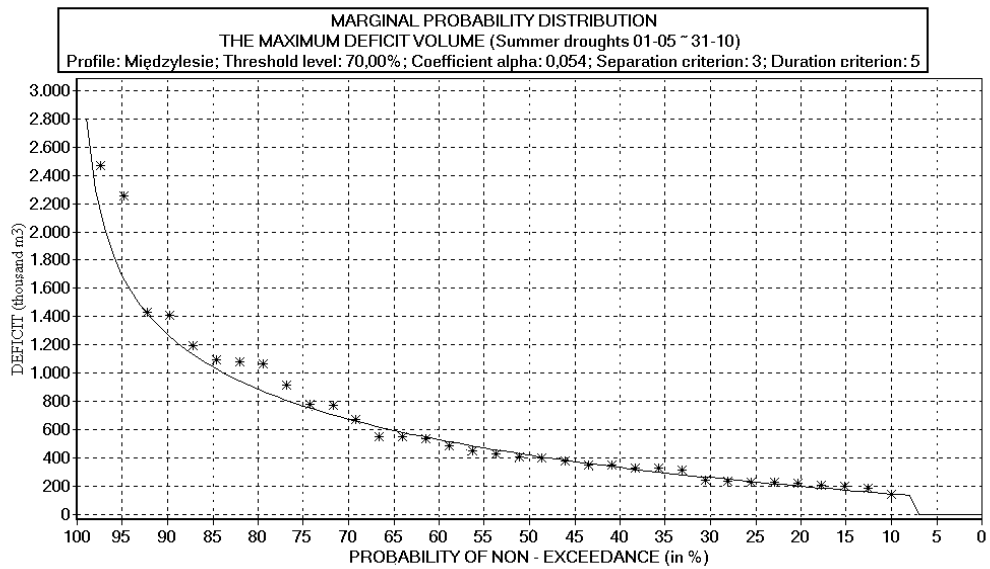

HESSD

3, 859-893, 2006

\section{Bivariate distribution of the low flow \\ extremes estimation}

W. Jakubowski

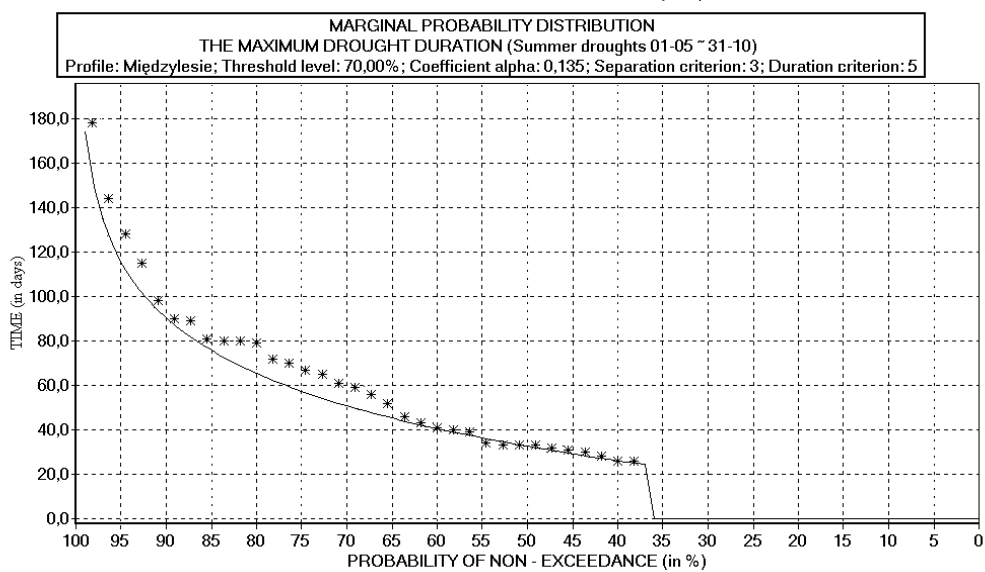

Title Page

Abstract

Introduction

Conclusions

References

Tables

Figures

14

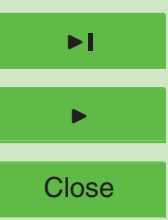

Back

Close

Full Screen / Esc

Printer-friendly Version

Fig. 11. The Nysa Klodzka River, Międzylesie profile; a summer low flows - fitting into marginal distributions of the low flow maximum deficit volume and duration.

Interactive Discussion 


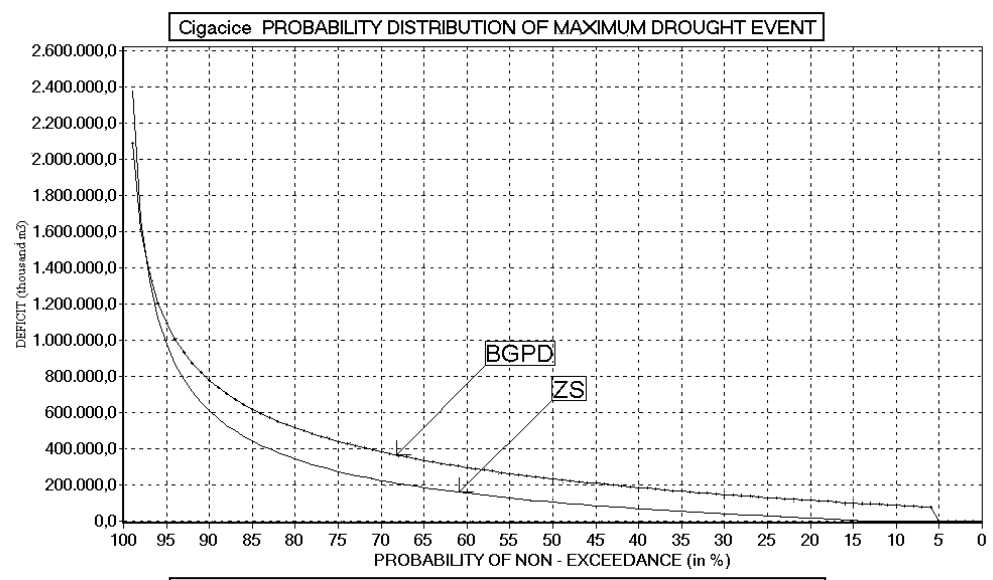

HESSD

3, 859-893, 2006

\section{Bivariate distribution of the low flow \\ extremes estimation}

W. Jakubowski

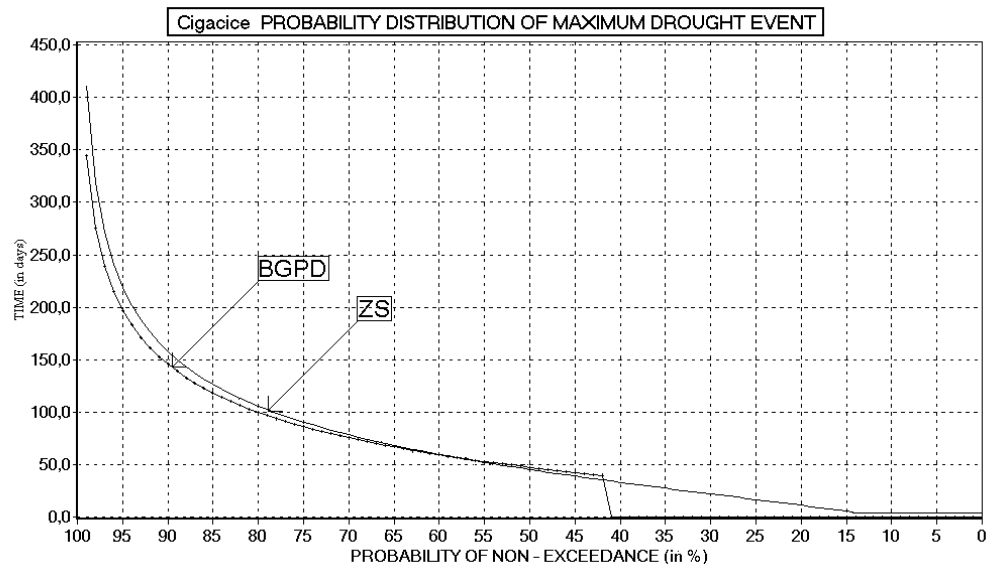

Title Page

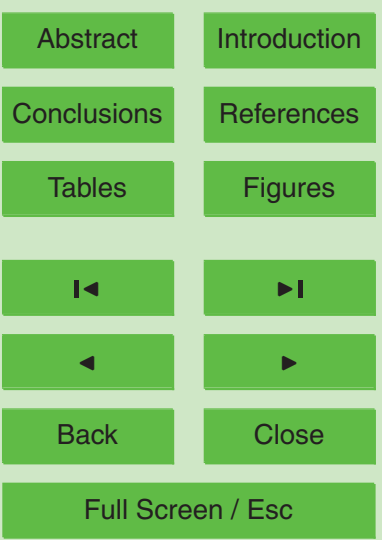

Printer-friendly Version

Fig. 12. The Odra River, Cigacice profile; an annual low flows - comparison between the low flow deficit and duration quantiles obtained by fitting into the BGPD and ZS model.

Interactive Discussion 


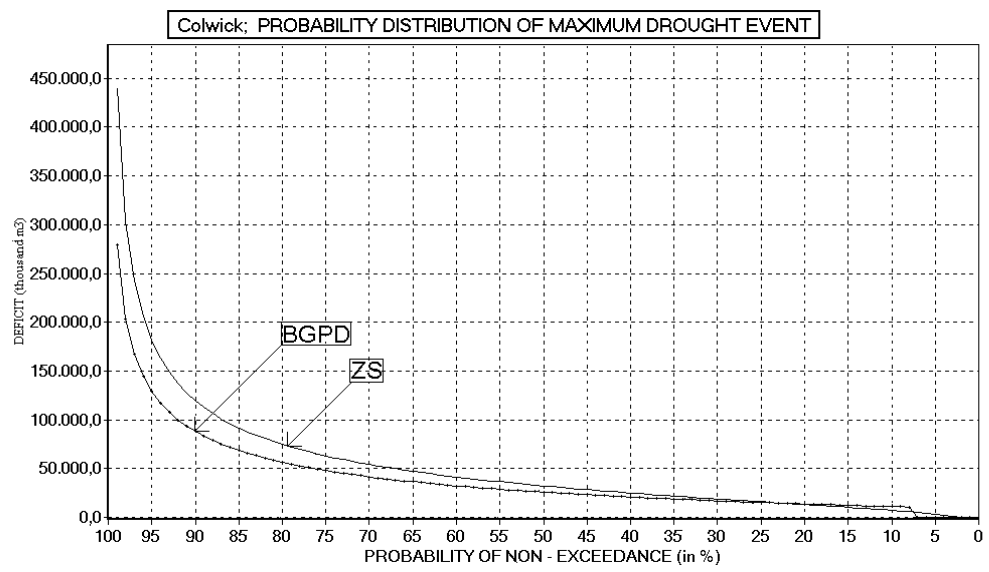

HESSD

3, 859-893, 2006

\section{Bivariate distribution of the low flow \\ extremes estimation}

W. Jakubowski

Title Page

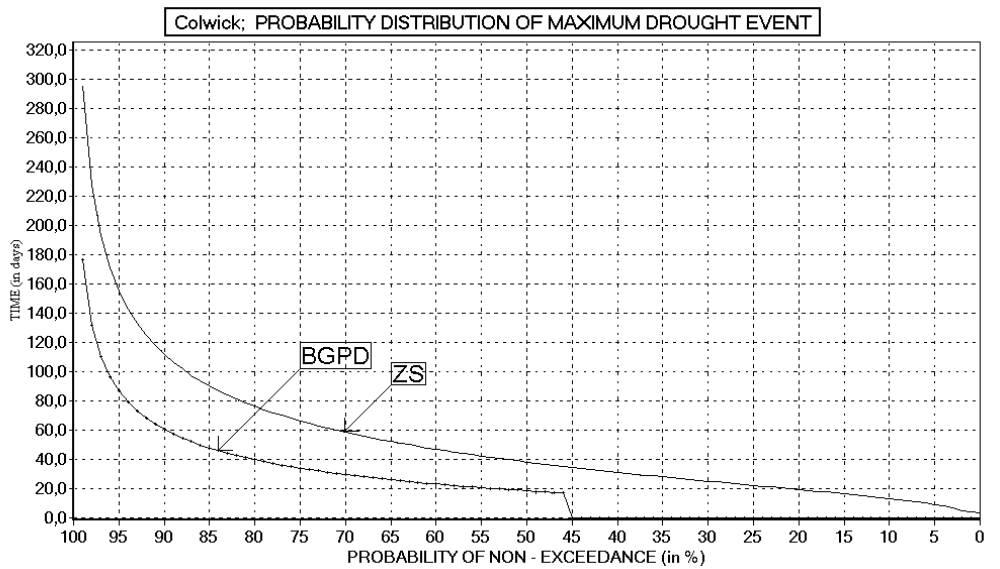

Abstract

Introduction

Conclusions

References

Tables

Figures

14

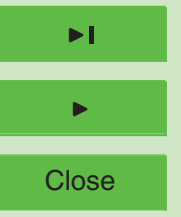

Back

Close

\section{Full Screen / Esc}

Printer-friendly Version

Fig. 13. The Trent River, Colwick profile; an annual low flows - comparison between the low

Interactive Discussion flow deficit and duration quantiles obtained by fitting into the BGPD and ZS models. 


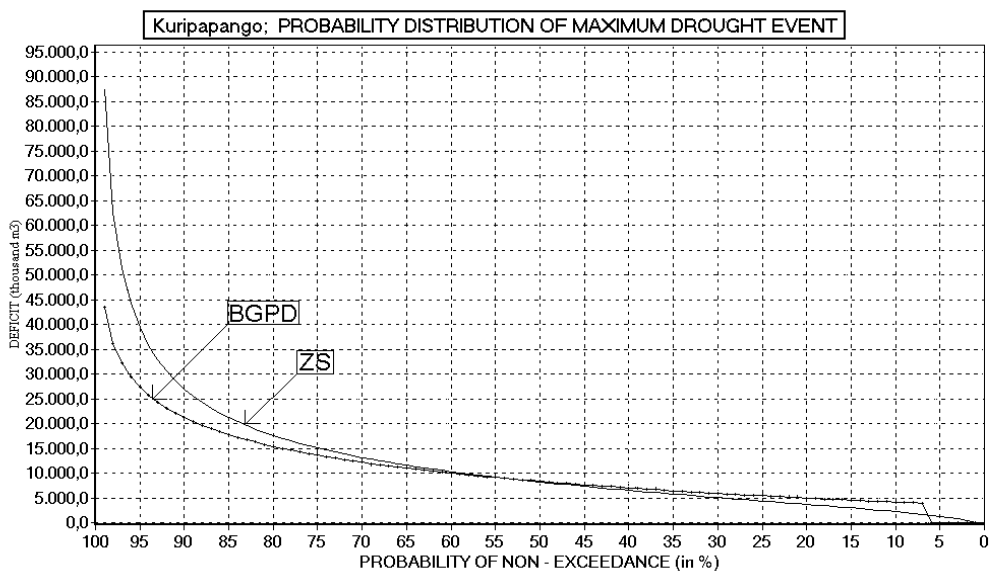

HESSD

3, 859-893, 2006

\section{Bivariate distribution of the low flow \\ extremes estimation}

W. Jakubowski

Title Page

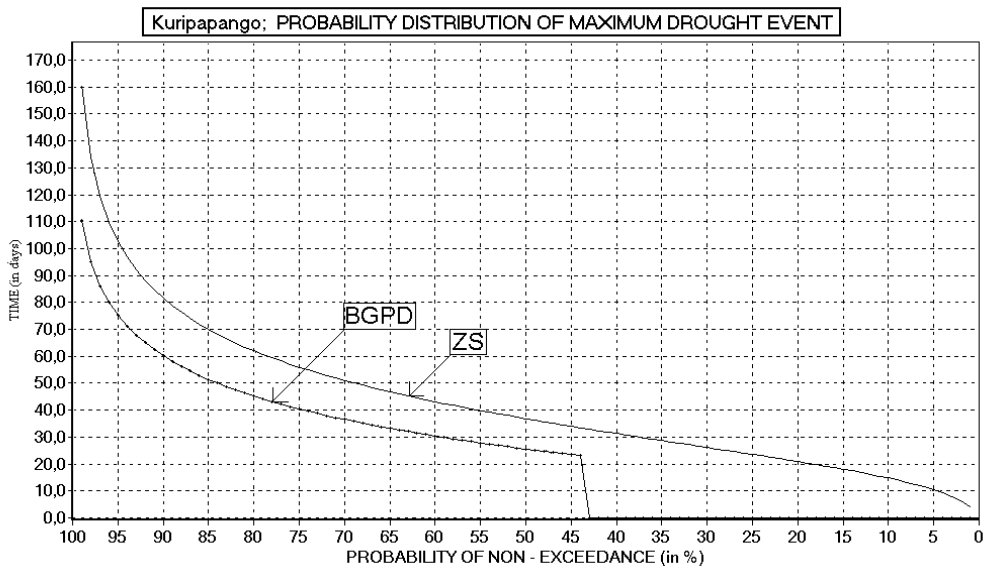

Abstract

Introduction

Conclusions

References

Tables

Figures

14

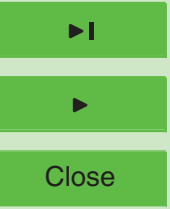

Back

Close

Full Screen / Esc

Printer-friendly Version

Fig. 14. The Ngaruroro River, Kuripapango profile; an annual low flows - comparison between

Interactive Discussion the low flow deficit and duration quantiles obtained by fitting into the BGPD and ZS models. 


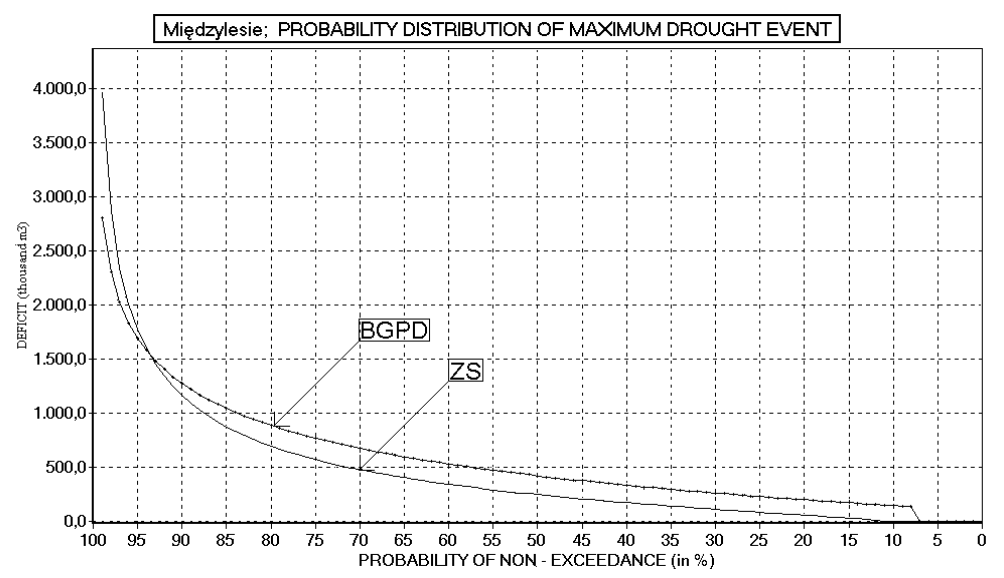

HESSD

3, 859-893, 2006

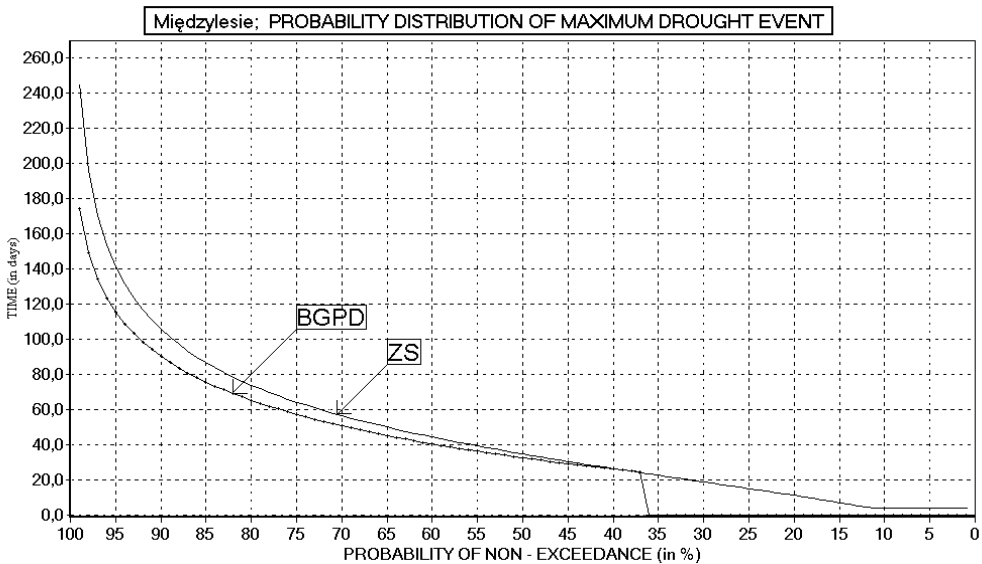

Title Page

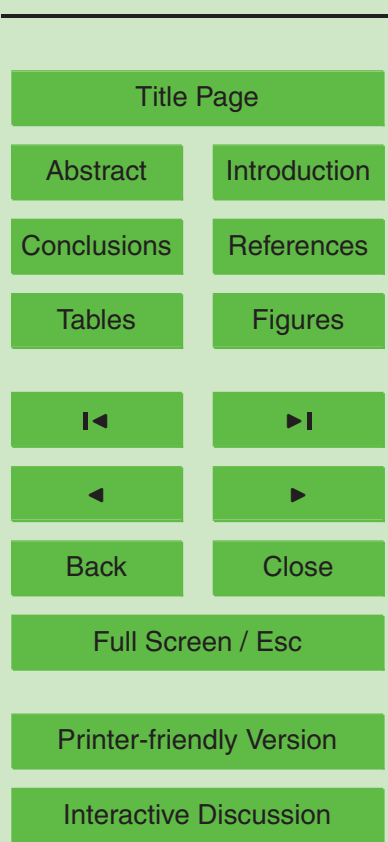

Printer-friendly Version

Fig. 15. The Nysa Klodzka River, Międzylesie profile; a summer low flows - comparison between the low flow deficit and duration quantiles obtained by fitting into the BGPD and ZS models.

\section{Bivariate distribution of the low flow \\ extremes estimation}

W. Jakubowski 